progesterone receptor. Mol. Endocrinol. 11, 1114-1128 (1997).

16. DeMarzo, A. M., Onate, S. A., Nordeen, S. K. \& Edwards, D. P. Effects of the steroid antagonist RU486 on dimerization of the human progesterone receptor. Biochemistry 31, 10491-10501 (1992).

17. Skafar, D. F. Dimerization of the RU486-bound calf uterine progesterone receptor. J. Steroid Biochem. Mol. Biol. 44, 39-43 (1993).

18. Edwards, D. P. et al. Progesterone receptor and the mechanism of action of progesterone antagonists. J. Steroid Biochem. Mol. Biol. 53, 449-458 (1995).

19. Benhamou, B. et al. A single amino acid that determines the sensitivity of progesterone receptors to RU486. Science 255, 206-209 (1992).

20. Zenke, M., Munoz, A., Sap, J., Vennstrom, B. \& Beug, H. v-erbA oncogene activation entails the loss of hormone-dependent regulator activity of c-erba. Cell 61, 1035-1049 (1990).

21. Durand, B. et al. Activation function $2(\mathrm{AF}-2)$ of retinoic acid receptor and 9-cis retinoic acid receptor: presence of a conserved autonomous constitutive activating domain and influence of the nature of the response element on AF-2 activity. EMBO J. 13, 5370-5382 (1994).

22. LeDouarin, B. et al. Ligand-dependent interaction of nuclear receptors with potential transcriptional intermediary factors (mediators). Phil. Trans. R. Soc. Lond. B 351, 569-578 (1996).

23. Thenot, S., Henriquet, C., Rochefort, H. \& Cavailles, V. Differential interaction of nuclear receptors with the putative human transcriptional coactivator hTIF1. J. Biol. Chem. 272, 12062-12068 (1997).

24. Collingwood, T. et al. A natural transactivation mutation in the thyroid hormone beta receptor: impaired interaction with putative transcriptional mediators. Proc. Natl Acad. Sci. USA 94, 248-253 (1997)

25. Jeyakumar, M., Tanen, M. \& Bagchi, M. Analysis of the functional role of steroid receptor coactivator-1 in ligand-induced transactivation by thyroid hormone receptor. Mol. Endocrinol. 11, 755-767 (1997).

26. Vegeto, E. et al. The mechanism of RU486 antagonism is dependent on the conformation of the carobxy-terminal tail of the human progesterone receptor. Cell 69, 703-713 (1992).

27. Otwinowski, Z. \& Minor, W. Processing X-ray diffraction data collected in oscillation mode. Meth Enzymol. 276, 307-326 (1997).

28. Wishart, D., Boyko, R. \& Sykes, B. Constrained multiple sequence alignment using XALIGN. Cabio $10,687-688(1994)$

Supplementary information is available on Nature's World-Wide Web site (http://www.nature.com) or as paper copy from the London editorial office of Nature.

Acknowledgements. We thank M.-J. Tsai and B. O'Malley for the cDNA fragment containing the coding segment for the protein used here; C. Ogata (X4A-NSLS), L. Berman (X25-NSLS) and S. Ealick (CHESS) for access to and help with synchrotron radiation; R. Fletterick and D. Moras for useful structural information; D. Tanenbaum and Y. Wang for access to and discussions about their crystal structure of the oestradiol-ER-LBD complex; and members of P.B.S.'s laboratory for help with data collection. This work was supported in part by an NIH grant.

Correspondence and requests for materials should be addressed to P.B.S. (e-mail: sigler@csb.yale.edu). Coordinates have been deposited in the PDB under accession number la28.

\section{corrections}

\section{Low nitrate: phosphate ratios in the global ocean}

\section{T. Tyrrell \& C. S. Law}

Nature 387, 793-796 (1997)

See the Scientific Correspondence contribution on page 318 of this issue in which-owing to the discovery of errors in the international database on which this paper was based-the authors retract their main new conclusions.

\section{A caspase-activated DNase that degrades DNA during apoptosis, and its inhibitor ICAD}

\section{Masato Enari, Hideki Sakahira, Hideki Yokoyama, Katsuya Okawa, Akihiro Iwamatsu \& Shigekazu Nagata}

Nature 391, 43-50 (1998)

We have noticed that the sequence of murine CAD (Fig. 5d) carries an error. The sequence of the amino acids from 47 to 76 should read SRLCLYEDGTEVTDDCFPGLPNDAELLLL, instead of FPAVPVRRWHGGDGRLLPGPFPTTLSSYCF as published. The open reading frame of the cDNA (pEF-mCAD) consists of 344 amino acids instead of 345 amino acids, and the mature murine CAD is a protein of 342 amino acids with a calculated relative molecular mass of 39,214.18. The sequence for mouse CAD in the DDBJ/GenBank/ EMBL database (accession number AB009377) has been revised (24 February 1998). This mistake does not change the substance of our findings or the interpretation of our data.

\section{Phase-mapping of periodically domain-inverted $\mathrm{LiNbO}_{3}$ with coherent X-rays}

Z. W. Hu, P. A. Thomas, A. Snigirev, I. Snigireva, A. Souvorov, P. G. R. Smith, G. W. Ross \& S. Teat

Nature 392, 690-693 (1998)

The name of the first author on this Letter was incorrectly published as $\mathrm{Z}$. H. Hu.

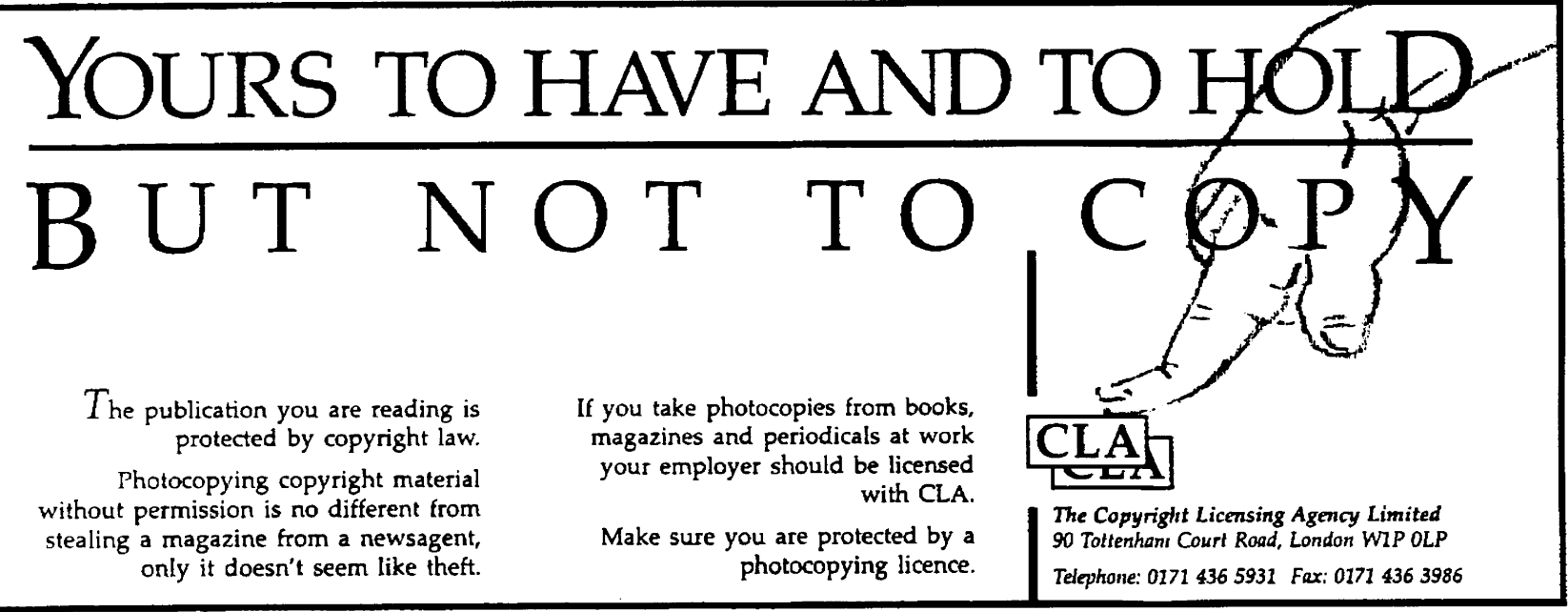


single-crystal $\mathrm{MoS}_{2}$ have over four times the shear strength of the terraces. The weak adhesion of the HNs to the mating surface were reflected in scanning force microscopy (SFM), whereby the HN particles were brushed away by the tip in contact mode imaging. Using the non-contact mode of the SFM, which avoids shear, clear images of the $\mathrm{HN}$ were obtained. Transmission electron microscope (TEM) analysis of the HNs which had gone through extensive wear experiments revealed that many of them had lost their outer $\mathrm{WS}_{2}$ shells, but that they had nevertheless preserved their overall cage shape. In contrast, the $2 \mathrm{H}$ material underwent extensive structural damage, amorphization and oxidation. Consequently, improved tribological behaviour of the $\mathrm{HNs}$, attributed to rolling friction and absence of dangling bonds, is not lost until complete destruction of the particles occurs. The slower deterioration of the HNs is reflected by their lower wear rates, even after 12 hours of sliding (Fig. 2 legend).

The experimental results (rows 6, 7 and 8 of Table 1) clearly show that both $\mu$ and $w$ increase with decreasing size of the $2 \mathrm{H}$ platelets. This observation is in agreement with the suggestion that dangling bonds mediate friction in metal dichalcogenides: as the average size of the platelets decreases, the total surface area and hence the amount of dangling bonds on the reactive $\left(\|_{c}\right)$ surface increases. In contrast, the friction coefficient of the much smaller $\mathrm{HN}$ particles, which do not expose dangling bonds, is less than that of any of the different $2 \mathrm{H}$ particle mixtures. A decrease in particle size also tends to increase viscosity, which usually entails higher friction $^{13}$. The HN mixture had the highest viscosity, and normalizing for this parameter would therefore give an even stronger indication of the enhanced performance of the $\mathrm{HN}$ material, relative to $2 \mathrm{H}-\mathrm{MoS}_{2}$ and $2 \mathrm{H}-\mathrm{WS}_{2}$.

The synthesis of $\mathrm{HN}-\mathrm{WS}_{2}$ uses abundant precursors and fairly straightforward conditions, and the cost of the material is therefore not expected to prohibit large-scale applications in the automotive and aerospace industry, which currently use the apparently inferior dichalcogenides. Improved control of the size distribution and shape of the nanoparticles is expected to lead to improved tribological properties. Furthermore, $\mathrm{HN}-\mathrm{MoS}_{2}$ might be expected to outperform $\mathrm{HN}-\mathrm{WS}_{2}$, by analogy with their platelet counterparts. Clearly, alternative synthetic routes for the production of $\mathrm{HN}$ materials could yield solid lubricants with further improved properties.

Received 6 December 1996; accepted 21 April 1997.

1. Singer, I. L. in Fundamentals of Friction: Macroscopic and Microscopic Processes (eds Singer, I. L. \& Pollock, H. M.) 237 (Kluwer, Dordrecht, 1992).

2. Bowden, F. P. \& Tabor, D. Friction: An Introduction to Tribology 91 (Anchor, Garden City, New York, 1973).

3. Tenne, R., Margulis, L., Genut, M. \& Hodes, G. Polyhedral and cylindrical structures of tungsten disulphide. Nature 360, 444-445 (1992).

4. Feldman, Y., Wasserman, E., Srolovitz, D. J. \& Tenne, R. High-rate, gas-phase growth of $\mathrm{MoS}_{2}$ nested inorganic fullerenes and nanotubes. Science 267, 222-225 (1995).

Feldman, Y. et al. Bulk synthesis of inorganic fullerene-like $\mathrm{MS}_{2}(\mathrm{M}=\mathrm{Mo}, \mathrm{W})$ from the respective trioxide and the reaction mechanism. $J$. Am. Chem. Soc. 118, 5362-5367 (1966).

6. Standard G77 in ASTM Book of Standards Vol. 3.02, Wear and Erosion: Metal Corrosion 303-314 (Am. Soc. for Testing and Materials, West Conshohocken, PA, 1993).

Seitzman, L. E., Bolster, R. N., Singer, I. L. \& Wegand, J. C. Relationship of endurance to microstructure of $\mathrm{MoS}_{2}$ coatings. Tribology Trans. 38, 445-451 (1995).

8. Moser, J. \& Lévy, F. $\mathrm{MoS}_{2-\mathrm{x}}$ lubricating films: structure and wear mechanisms investigated by crosssectional transmission electron microscopy. Thin Solid Films 228, 257-260 (1993).

9. Srolovitz, D. J., Safran, S. A., Homyonfer, M. \& Tenne, R. Morphology of nested fullerenes. Phys. Rev. Lett. 74, 1779-1781 (1995)

10. Fischer, T. E. in Fundamentals of Friction: Macroscopic and Microscopic Processes (eds Singer, I. L. \& Pollock, H. M.) 299 (Kluwer, Dordrecht, 1992).

11. Meyer, E. et al. Site-specific friction force spectroscopy. J. Vac. Sci. Technol. B 14, 1285-1288 (1996)

12. Mamin, H. J., Ganz, E., Abraham, D. W., Thomson, R. E. \& Clarke, J. Contamination-mediated deformation of graphite by the scanning tunneling microscope. Phys. Rev. B 34, 9015-9018 (1986).

13. Klein, J. Shear, friction, and lubrication forces between polymer-bearing surfaces. Anпи. Rev. Mater. Sci. 26, 581-612 (1996).

Supplementary Information is available on Nature's World-Wide Web site (http://www.nature.com) or as paper copy from Mary Sheehan at the London editorial office of Nature.

Acknowledgements. We thank D. J. Srolovitz for discussions. This work was supported in part by the ACS-PRF; the UK-Israel Science and Technology Research Fund; the Minerva Foundation (Munich); and the Israel Ministry of Science (Strategic Program on Nanomaterials).

Correspondence and requests for materials should be addressed to R.T. (e-mail: cpreshef@weizmann. weizmann.ac.il).

\section{Low nitrate : phosphate ratios in the global ocean}

\section{T. Tyrrell $*$ \& C. S. Law $\dagger$}

* Department of Oceanography, Southampton Oceanography Centre, University of Southampton, European Way, Southampton SO14 3ZH, UK $\dagger$ Plymouth Marine Laboratory, Prospect Place, Plymouth PL1 3DH, UK

The distribution and availability of the nutrients nitrate and phosphate exert a strong control over primary production in the world ocean. Here we use a recently compiled global data set of oceanographic observations ${ }^{1}$ - a database that is at least 40 times larger than currently used data sets (for example, ref. 2) - to analyse the variation of the nitrate : phosphate concentration ratio with depth and geographical location. Although the nutrient distributions confirm the dominant influence of aerobic decomposition, in agreement with the observations of Redfield ${ }^{3}$, we also identify a hitherto unreported secondary trend at low nitrate: phosphate ratio $(\sim 2-3)$. These conditions of low nitrate : phosphate ratio are associated with low oxygen concentrations and are probably caused by denitrification. Examination of the geographical distribution of these low nitrate:phosphate data suggests that denitrification in the western and northern North Pacific Ocean may have been previously overlooked, and that a reassessment of the global oceanic denitrification budget may therefore be required.

The World Ocean Atlas 1994 (WOA94) data set ${ }^{1}$ is an international collection of oceanographic information covering the past 60 years. Part of this data set has previously been used to construct global contour plots of nitrate, phosphate and silicate concentrations at several depths ${ }^{4}$. Here the 681,381 points in the data set are used to produce a scatter plot (Fig. 1) of the concentrations of nitrate $\left(\mathrm{NO}_{3}^{-}\right)$versus phosphate $\left(\mathrm{PO}_{4}^{3-}\right)$, which is then analysed. Despite the broad spatial and temporal range of the data, three features are clearly apparent. (1) A strong trend along a line of slope $\left[\mathrm{NO}_{3}^{-}\right] \approx(14-15)\left[\mathrm{PO}_{4}^{3-}\right]$. (2) A positive $x$-axis intercept of this main trend, that is, a predominance of points near to the $\left[\mathrm{NO}_{3}^{-}\right]=0$ axis rather than near to the $\left[\mathrm{PO}_{4}^{3-}\right]=0$ axis. (3) A weaker trend along lines with slopes $\left[\mathrm{NO}_{3}^{-}\right] \approx 2\left[\mathrm{PO}_{4}^{3-}\right]$. A least absolute deviation best-fit line ${ }^{31}$ to all of the data except the weaker trend (defined below in equation (2)) actually produces $\left[\mathrm{NO}_{3}^{-}\right]=14.1\left[\mathrm{PO}_{4}^{3-}\right]-1.53$ (with a mean absolute $\left[\mathrm{NO}_{3}^{-}\right]$deviation of each point from the best-fit line of $3.15 \mu \mathrm{mol} \mathrm{NO} \mathrm{Ng}^{-1}$ ), although the data is biased towards surface waters (where there has been more sampling). Analysis of only the points below $1,000 \mathrm{~m}$ (again excluding points in the weaker trend) reveals an average deep-sea $\left[\mathrm{NO}_{3}^{-}\right]$: $\left[\mathrm{PO}_{4}^{3-}\right]$ ratio of 14.6.

The main trend in the data with slope $\left[\mathrm{NO}_{3}^{-}\right] \approx(14-15)\left[\mathrm{PO}_{4}^{3-}\right]$ is due to phytoplankton assimilation of the nutrients in surface waters followed by aerobic decomposition of the sinking organic matter ${ }^{3}$, which recycles nitrogen and phosphorus back into dissolved form in deeper water according to the reaction ${ }^{5}$ :

$$
\begin{gathered}
\mathrm{C}_{106} \mathrm{H}_{175} \mathrm{O}_{42} \mathrm{~N}_{16} \mathrm{P}+150 \mathrm{O}_{2} ! \\
106 \mathrm{CO}_{2}+16 \mathrm{HNO}_{3}+\mathrm{H}_{3} \mathrm{PO}_{4}+78 \mathrm{H}_{2} \mathrm{O}
\end{gathered}
$$

Some scatter about a straight line is to be expected due to variation in the nitrate: phosphate ratios of the plankton being decomposed ${ }^{6}$, localized riverine input and other factors. The positive $x$-intercept of the main trend in the data agrees with the observed predominance of nitrogen over phosphorus limitation at low nutrient concentrations in surface waters ${ }^{7,8}$.

The most surprising aspect of the data is the weaker trend along lines with slopes $\left[\mathrm{NO}_{3}^{-}\right]:\left[\mathrm{PO}_{4}^{3-}\right] \approx 2.0$. This trend can be seen 
clearly in a profile of $\left[\mathrm{NO}_{3}^{-}\right]:\left[\mathrm{PO}_{4}^{3-}\right]$ against depth (Fig. 2). This feature is not remarked upon in previous nitrate:phosphate analyses $^{3,9-11}$ because it is not apparent in the smaller data sets ${ }^{2}$ which these studies have used.

To investigate this new phenomenon, a subset of the data containing the points contributing to the secondary nitrate: phosphate trend was extracted according to the following criteria:

$$
\left[\mathrm{PO}_{4}^{3-}\right]>1.5 \mu \mathrm{mol} \mathrm{kg}{ }^{-1} \text { and }\left[\mathrm{NO}_{3}^{-}\right] /\left[\mathrm{PO}_{4}^{3-}\right]<3.0
$$

(the shaded area in Fig. 1 inset). These criteria were chosen so as to include points at low nitrate: phosphate, but to exclude points that are only a short 'distance' away from the predominant trend in the data. For example, only a minor system perturbation or measurement error is required at lower nutrient concentrations for the nitrate: phosphate ratio to change from 15 to 2, and so our criteria only include low nitrate:phosphate ratios at higher phosphate concentrations. The low nitrate: phosphate (LNP) points resulting from this definition make up $1.8 \%$ of the total $(12,469$ points out of 681,381). The geographical distribution of these LNP points can be plotted (Fig. 3). Relationships with other parameters (Fig. 4) show whether the LNP points occur preferentially under certain conditions or at certain times.

The first explanation to consider for the LNP points is whether they are due solely to instrument error, for example, associated with older nutrient measurement techniques. However, there is no strong pattern in the yearly distribution of the LNP points (Fig. $4 a)$, with a large fraction $(37 \%=4,599)$ of them being made during the past 20 years. In addition, the LNP measurements were made during cruises by many different nations, using different methodologies, in almost all oceans, and across a range of depths. LNP

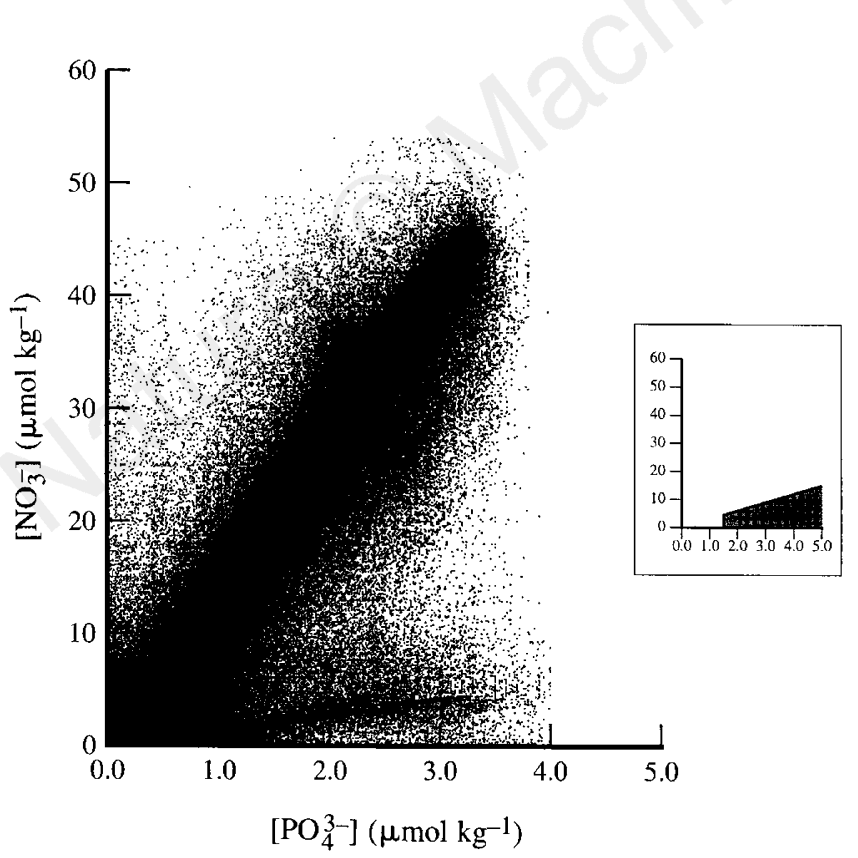

Figure 1 Scatter plot of nitrate concentration versus phosphate concentration in the global ocean, with the data points taken from ref. 1. Data were subjected to screening procedures by the National Oceanographic Data Center (NODC) before being included; historical data sets were recovered and included subject to reliability ${ }^{30}$. The data comes from 68,341 different stations during cruises by 51 different countries. Only data points with no error flags are used here. Only actual measured values are used, with no interpolations being included. Observations were only included when both nitrate and phosphate were measured simultaneously, that is from the same bottle. The upper limit for phosphate in ref. 1 is $4.0 \mu \mathrm{mol} \mathrm{kg}{ }^{-1}$. The shaded area in the inset shows the subset of the data designated as low nitrate: phosphate ratio (LNP ratio). points are detected by cruises visiting the same area many years apart. For instance, LNP points have been detected independently in the western North Pacific $\left(110-180^{\circ} \mathrm{E}, 0-60^{\circ} \mathrm{N}\right)$ by Japanese, Taiwanese, USA, Chinese, USSR, Thai and Indonesian cruises in 1949, 1958 and in 21 out of the 24 years between 1963 and 1986. LNP points and normal (nitrate: phosphate $\approx 15$ ) points were often measured at different depths within the same profile. There is strong spatial coherence (clustering) of the LNP points (Fig. 3), and they possess a spatial distribution which is different from that of the data set as a whole. There is a definite correlation with oxygen concentrations (Fig. 4b). Instrument error can be discounted as a possible cause of the LNP points.

Because the low nitrate: phosphate ratios are genuine, what could have caused them? Examination of global nitrate: silicate and silicate:phosphate plots (not shown) reveal a low trend in the former but not a low trend in the latter, so the low nitrate: phosphate ratios are caused by low nitrate, not high phosphate. As the nitrate: phosphate ratio of river water is generally greater than that of the Redfield ratio ${ }^{12}$, and values of this ratio in phytoplankton biomass of $<3$ have not been reported ${ }^{6}$, this suggests that a nitrate removal process is responsible for the LNP points.

In particular, denitrification is usually assumed to be the explanation for low nitrate: phosphate ratios ${ }^{9,11,13}$. Anaerobic decomposition by denitrifying bacteria alters the nutrient concentrations in the water according to a reaction similar to ${ }^{14,15}$ :

$$
\begin{gathered}
\mathrm{C}_{106} \mathrm{H}_{175} \mathrm{O}_{42} \mathrm{~N}_{16} \mathrm{P}+104 \mathrm{HNO}_{3} ! \\
106 \mathrm{CO}_{2}+60 \mathrm{~N}_{2}+\mathrm{H}_{3} \mathrm{PO}_{4}+138 \mathrm{H}_{2} \mathrm{O}
\end{gathered}
$$

Denitrification is more likely to dominate in low-oxygen waters, although it can still be operative in more oxic waters within the

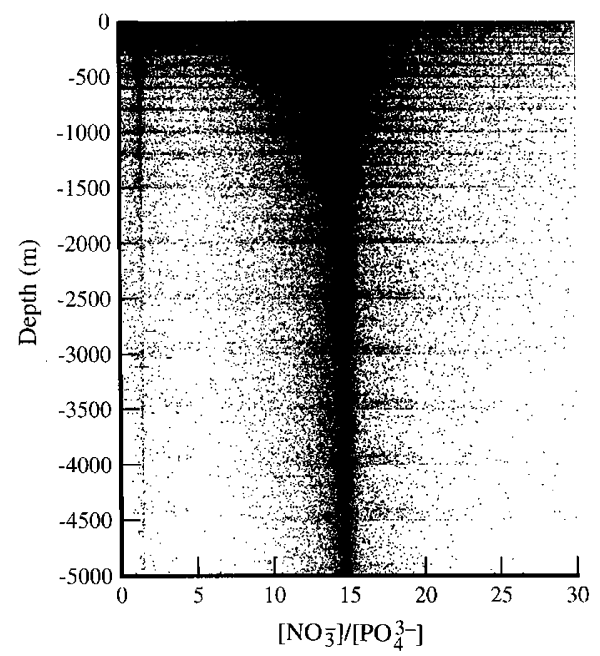

Figure 2 Scatter plot of the nitrate: phosphate ratio versus depth in the global ocean (after ref. 10), using the same data as in Fig. 1. 
anoxic micro-sites in particulate matter ${ }^{16}$. The geographical distribution of LNP points (Fig. 3) provides further supporting evidence of denitrification as the source process, with LNP points predominantly observed in low-oxygen-prone coastal areas and regions of open-ocean low oxygen associated with upwelling waters.

The LNP points correspond to large nitrate deficits of between 18 and $45 \mu \mathrm{mol} \mathrm{kg}{ }^{-1}$ relative to nitrate : phosphate $=15$, and the nitrogen in the missing nitrate must have been converted into some other form of nitrogen. Neither ammonium or nitrite ${ }^{17}$ are detected at such high concentrations in oxic or sub-oxic waters. However, $\mathrm{N}_{2}$, the end-product of denitrification, is present at concentrations of $\sim 1,200 \mu \mathrm{mol} \mathrm{kg}^{-1}$ due to equilibration with the large atmospheric reservoir. Large amounts of nutrients may also exist in dissolved organic form (dissolved organic nitrogen, DON, and dissolved organic phosphorus, DOP), but there is no reason to suspect an increase in DON without a simultaneous increase in DOP, or that this should be correlated with low oxygen. Other nitrogen species in the oceans are only present at trace concentrations, and so conservation of nitrogen also suggests that a flux of $\mathrm{NO}_{3}^{-}$to $\mathrm{N}_{2}$ via denitrification is the most likely cause of the shortfalls in $\mathrm{NO}_{3}^{-}$in the LNP points.

From the arguments above, removal of $\mathrm{NO}_{3}^{-}$by denitrification seems by far the most plausible explanation, and the LNP points should therefore be able to be used as indicators of denitrification.

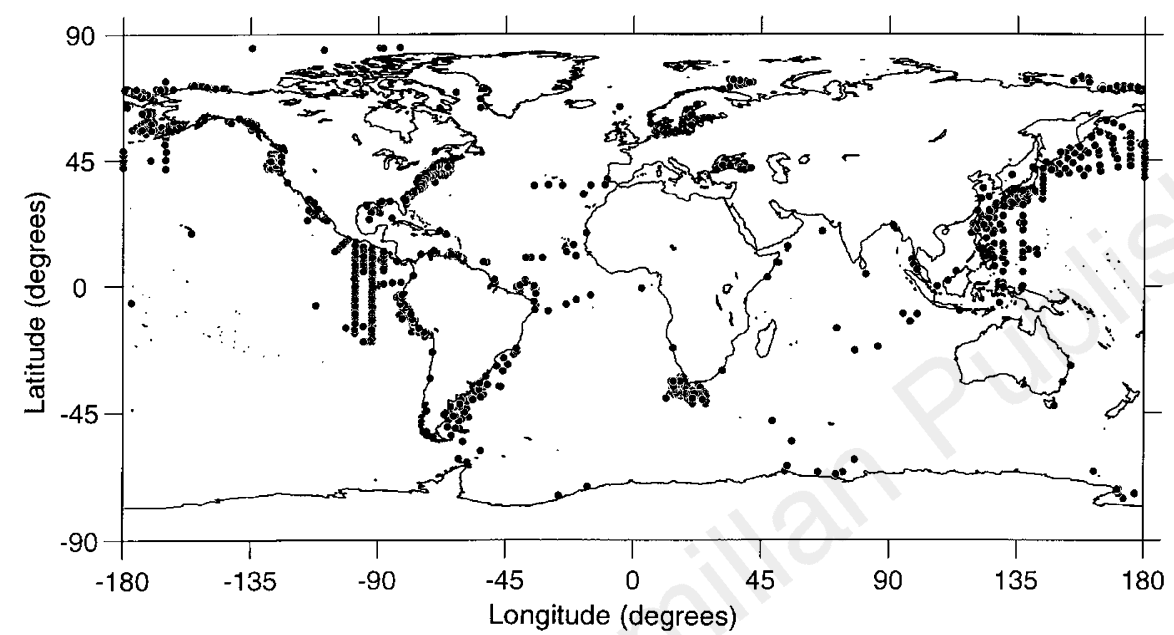

Figure 3 Geographical locations where (at any depth) measured phosphate concentration was $>1.5 \mu \mathrm{mol} \mathrm{kg}{ }^{-1}$ and the ratio of measured nitrate to measured phosphate concentrations was $<3.0$. (Data taken from Ref. 1). The distribution can be compared to a similar plot $^{13}$ using an earlier and smaller NODC data set and using a different LNP criterion $\left(\left[\mathrm{NO}_{3}^{-}\right]<\left(\left(15\left[\mathrm{PO}_{4}^{3-}\right]\right)-10.0\right)\right)$.
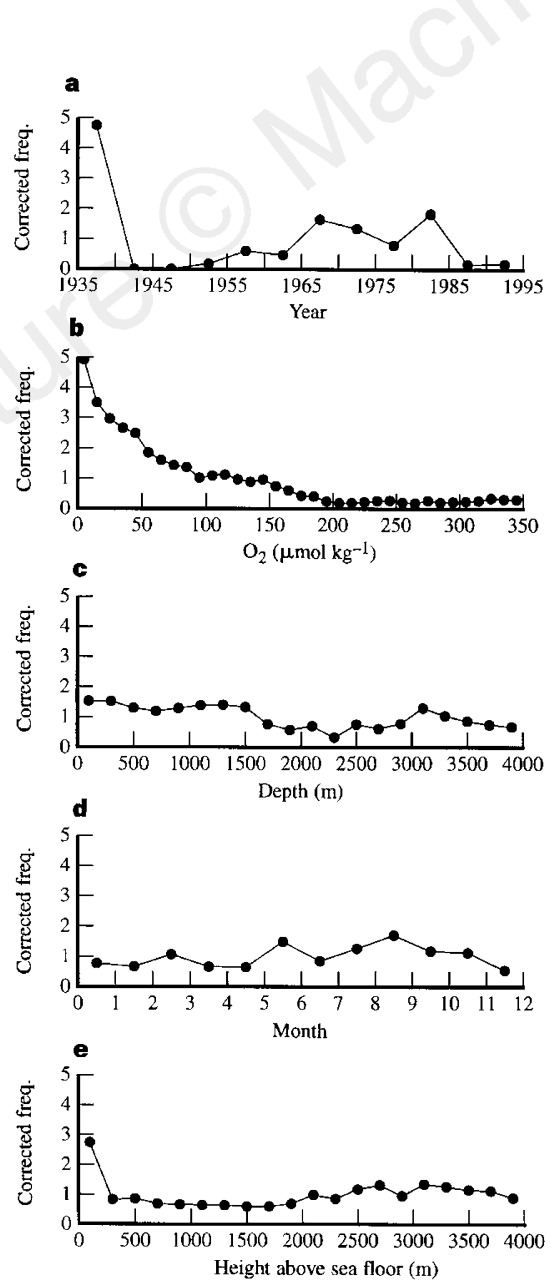

Figure 4 Frequency plots of the LNP points against: year of measurement (a); oxygen concentration (b); depth (c); month of the year (d); and height above sea floor $(\mathbf{e})$. In each case the $y$-ordinate is calculated as $y=\left(L_{N P_{x}} / L N P_{\text {tot }}\right) /\left(N P_{x} / N P_{\text {tot }}\right)$. Here $\left(L N P_{x} / L N P_{\text {tot }}\right)$ is the fraction of $L N P$ points occurring at the value or range of the parameter plotted on the $x$-axis, and $\left(N P_{x} / N P_{\text {tot }}\right)$ is the fraction of all points occurring at the same value or range. As an example, they-ordinate of the left-most point in $\mathbf{b}$ is calculated as $(1,186 / 10,890) \div(9,742 / 613,169)$ because 10,890 of the LNP points and 613,169 of all the nitrate: phosphate points in the data set were measured at times when oxygen was also measured, and of those, 1,186 of the LNP points and 9,742 of the whole set of points were at oxygen concentrations of 0$20 \mu \mathrm{mol} \mathrm{kg}{ }^{-1}$. To ensure that the frequency plots are fully inter-comparable, the $y$-ordinates were then normalized so that the average $y$-ordinate for each plot is 1.0. The high correlation during 1935-40 in a is not significant as only 7 LNP points were measured during that period. The correlations in $\mathbf{e}$ are less reliable because seafloor depths for each station are not available in ref. 1 and so had to be obtained instead by interpolation from values in a separate data set, at $(1 / 12) \times(1 / 12)$ degree resolution. 
In those areas where denitrification is identified in this way (clusters of LNP points in Fig. 3) the denitrification may be occurring in the water column ${ }^{18,19}$ or within the sediment ${ }^{15,20}$, with subsequent exchange of substrates and products with the overlying waters. Open-ocean denitrification has been reported in the eastern tropical North Pacific ${ }^{21}$, the eastern tropical South Pacific ${ }^{14}$, and in the Arabian $\mathrm{Sea}^{22}$. Our criteria (equation (2)) identify the eastern tropical Pacific (north and south), but not the Arabian Sea. The Arabian Sea does not appear as a denitrification site because, although denitrification takes place, the nitrate:phosphate ratio does not fall much below 9.0 as a result ${ }^{22}$. In light of this, it is clear that the method used here will detect the majority of denitrificationaffected waters, but not all of them.

It has previously been suggested, from nitrogen deficit calculations, that denitrification is taking place within the northern North Pacific $^{23}$ and the Bering Sea ${ }^{24}$, but nevertheless these areas are not traditionally recognized as major sites of denitrification. The calculations reported here provide additional evidence for denitrification in these places, and additionally across large areas of the western North Pacific (Fig. 3). Nitrate concentrations are generally high ${ }^{4}$ and oxygen concentrations $\operatorname{low}^{25,26}$ in sub-surface waters in these areas, providing favourable conditions for denitrification ${ }^{27}$.

Assuming similar denitrification rates per unit area, the extent of the LNP points (Fig. 3) suggests that the total nitrate loss in the west and north North Pacific region is about 20\% higher than in the eastern tropical Pacific Ocean. Sedimentary denitrification contributes about half as much as water-column denitrification to the global flux ${ }^{20}$, and the eastern tropical Pacific (north and south) was previously estimated to contribute $\sim 85 \%$ of total water-column denitrification ${ }^{27}$. Therefore inclusion of the western and northern North Pacific could potentially increase the total global marine denitrification flux by about $70 \%$. This calculation is speculative, but it is clear that more detailed work should be carried out to enable more precise estimates to be made. Denitrification is the largest sink of reactive nitrogen from the oceans ${ }^{28,29}$, and is therefore a critical component in the global marine nitrogen cycle.

Received 12 August 1996; accepted 21 April 1997.

1. NODC World Ocean Atlas 1994 data set (http://www.nodc.noaa.gov/NODC-products.html).

2. Geochemical Oceans Section Study (GEOSECS) data set (http://ingrid.ldgo.columbia.edu/ SOURCES/.GEOSECS/).

Redfield, A. C. in James Johnston Memorial Volume 176-192 (Liverpool Univ. Press, 1934).

4. Levitus, S., Conkright, M. E., Reid, J. L., Najjar, R. G. \& Mantyla, A. Distribution of nitrate, phosphate and silicate in the world oceans. Prog. Oceanogr. 31, 245-273 (1993).

5. Anderson, L. A. On the hydrogen and oxygen-content of marine phytoplankton. Deep-Sea Res. I 42 1675-1680 (1995).

6. Copin-Montégut, C. \& Copin-Montégut, G. Stoichiometry of carbon, nitrogen, and phosphorous in marine particulate matter. Deep-Sea Res. 30, 31-46 (1983).

Smith, S. V. Phosphorus versus nitrogen limitation in the marine environment. Limnol. Oceanogr. 29, 1149-1160 (1984).

8. Codispoti, L. A. in Productivity of the Ocean: Present and Past (eds Berger, W. H., Smetacek, V. S. \& Wefer, G.) 377-394 (Wiley, New York, 1989).

9. Broecker, W. S. \& Peng, T.-H. Tracers in the Sea (Eldigio, New York, 1982)

10. Fanning, K. A. Nutrient provinces in the sea-concentration ratios, reaction-rate ratios, and ideal covariation. J. Geophys. Res. 97, 5693-5712 (1992).

11. Anderson, L. A. \& Sarmiento, J. L. Redfield ratios of remineralization determined by nutrient dataanalysis. Glob. Biogeochem. Cycles 8, 65-80 (1994).

12. Meybeck, M. in Interactions of C, N, P and S Biogeochemical Cycles and Global Change (eds Wollast, R., Mackenzie, F. T. \& Chou, L.) 163-193 (NATO ASI Ser., Vol. I 4, Springer, Berlin, 1993).

13. Kamykowski, D. \& Zentara, S.-J. Hypoxia in the world ocean as recorded in the historical data set. Deep-Sea Res. 37, 1861-1874 (1990)

14. Codispoti, L. A. \& Christensen, J. P. Nitrification, denitrification and nitrous oxide cycling in the eastern tropical South Pacific Ocean. Mar. Chem. 16, 277-300 (1985).

15. Canfield, D. E. in Interactions of C, N, P and S Biogeochemical Cycles and Global Change (eds Wollast, R., Mackenzie, F. T. \& Chou, L.) 333-363 (NATO ASI Ser., Vol. I 4, 1993).

16. Alldredge, A. L. \& Silver, M. W. Characteristics, dynamics and significance of marine snow. Prog. Oceanogr. 20, 41-82 (1988).

17. Kamykowski, D. \& Zentara, S.-J. Spatio-temporal and process-oriented views of nitrite in the world ocean as recorded in the historical data set. Deep-Sea Res. 38, 445-464 (1991).

18. Rönner, U. \& Sörensson, F. Denitrification rates in the low-oxygen waters of the Baltic proper. Appl. Environ. Microbiol. 50, 801-806 (1985).

19. Codispoti, L. A. et al. High nitrite levels off northern Peru: a signal of instability in the marine denitrification budget. Science 233, 1200-1202 (1986).

20. Christensen, J. P., Townsend, D. W. \& Montoya, J. P. Water column nutrients and sedimentary denitrification in the Gulf of Maine. Continent. Shelf Res. 16, 489-515 (1996).

21. Thomas, W. H. On denitrification in the northeastern tropical Pacific Ocean. Deep-Sea Res. 13, 1109 1114 (1966).

22. Mantoura, R. F. C. et al. Nitrogen biogeochemical cycling in the northwestern Indian Ocean. Deep-Sea Res. I 40, 651-671 (1993).
23. Tsunogai, S. in Biological Oceanography of the Northern North Pacific Ocean (eds Takenouti, A. Y. et al.) 517-533 (Idemitsu Shoten, Tokyo, 1972).

24. Tsunogai, S., Kusakabe, M., Iizumi, H., Koike, K. \& Hattori, A. Hydrographic features of the deep water in the Bering Sea-the sea of silica. Deep-Sea Res. 26, 641-659 (1979).

25. Levitus, S. \& Boyer, T. P. World Ocean Atlas 1994 Vol. 2, Oxygen (Atlas NESDIS 2, NOAA, Washington DC, 1994).

26. Ogura, N. Relation between dissolved organic carbon and apparent oxygen utilization in the Western North Pacific. Deep-Sea Res. 17, 221-231 (1970).

27. Hattori, A. in Nitrogen in the Marine Environment (eds Carpenter, E. \& Capone, D.) 191-232 (Academic, New York, 1983).

28. Jaffe, D. A. in Global Biogeochemical Cycles (eds Butcher, S. S., Charlson, R. J., Orians, G. H. \& Wolfe, G. V.) 263-284 (Academic, New York, 1992).

29. Mackenzie, F. T., Ver, L. M., Sabine, C., Lane, M. \& Lerman, A. in Interactions of C, N,P and S Biogeochemical Cycles and Global Change (eds Wollast, R., Mackenzie, F. T. \& Chou, L.) 1-61 (NATO ASI Ser., Vol. I 4, Springer, Berlin, 1993).

30. Conkright, M. E., Boyer, T. P. \& Levitus, S. Quality Control and Processing of Historical Nutrient Data (Tech. Rep. NESDIS 79, NOAA, Washington DC, 1994).

1. Press, W. H., Teukolsky, S. A., Vetterling, W. T. \& Flannery, B. P. Numerical Recipes in FORTRAN 2nd edn (Cambridge Univ. Press, 1992).

Acknowledgements. We thank D. Burton, C. Garside, D. Hydes and P. Wright for discussions; R. Mills, D. Hydes and M. Conkright for comments on the manuscript; and P. Challenor for sea-floor depth data.

Correspondence should be addressed to T.T. (e-mail: T.Tyrrell@soc.soton.ac.uk).

\section{Contrasting physiological and structural vegetation feedbacks in climate change simulations}

\section{Richard A. Betts ${ }^{\star}$, Peter M. Cox ${ }^{\star}$, Susan E. Lee $\dagger$ \& F. lan Woodward $\dagger$}

* Hadley Centre, Meteorological Office, Bracknell RG12 2SY, UK

$\dagger$ Department of Animal and Plant Sciences, University of Sheffield,

Sheffield S10 2TN, UK

Anthropogenic increases in the atmospheric concentration of carbon dioxide and other greenhouse gases are predicted to cause a warming of the global climate by modifying radiative forcing ${ }^{1}$. Carbon dioxide concentration increases may make a further contribution to warming by inducing a physiological response of the global vegetation-a reduced stomatal conductance, which suppresses transpiration ${ }^{2}$. Moreover, a $\mathrm{CO}_{2}$-enriched atmosphere and the corresponding change in climate may also alter the density of vegetation cover, thus modifying the physical characteristics of the land surface to provide yet another climate feedback ${ }^{3-6}$. But such feedbacks from changes in vegetation structure have not yet been incorporated into general circulation model predictions of future climate change. Here we use a general circulation model iteratively coupled to an equilibrium vegetation model to quantify the effects of both physiological and structural vegetation feedbacks on a doubled- $\mathrm{CO}_{2}$ climate. On a global scale, changes in vegetation structure are found to partially offset physiological vegetation-climate feedbacks in the long term, but overall vegetation feedbacks provide significant regionalscale effects.

The Sheffield University vegetation model simulates global vegetation under steady-state conditions of climate and atmospheric $\mathrm{CO}_{2}$ (ref. 7). It models the physiological processes of nutrient uptake, photosynthesis, respiration and stomatal limitation of transpiration, and uses these to determine the vegetation structural character in terms of foliage density. The outputs of this model are: (1) leaf area index (LAI), the area of leaf surface per unit area of ground; and (2) daytime mean canopy conductance $\left(g_{\mathrm{c}}\right)$, the net transpirational conductance of all stomata integrated (numerically) over the canopy depth. LAI is purely a structural variable, whereas $g_{c}$ contains both structural and physiological contributions. The 


\title{
A caspase-activated DNase that degrades DNA during apoptosis, and its inhibitor ICAD
}

\author{
Masato Enari ${ }^{\star}$, Hideki Sakahira*, Hideki Yokoyama*, Katsuya Okawa $\dagger$, Akihiro Iwamatsu $\dagger$ \& Shigekazu Nagata ${ }^{\star} \ddagger$ \\ * Department of Genetics, Osaka University Medical School, 2-2 Yamada-oka, Suita, Osaka 565, Japan \\ $\dagger$ Central Laboratories for Key Technology, Kirin Brewery Co., 1-13-5 Fukuura, Kanazawa, Yokohama, Kanagawa 236, Japan \\ $\ddagger$ Osaka Bioscience Institute, 6-2-4 Furuedai, Suita, Osaka 565, Japan
}

\begin{abstract}
The homeostasis of animals is regulated not only by the growth and differentiation of cells, but also by cell death through a process known as apoptosis. Apoptosis is mediated by members of the caspase family of proteases, and eventually causes the degradation of chromosomal DNA. A caspase-activated deoxyribonuclease (CAD) and its inhibitor (ICAD) have now been identified in the cytoplasmic fraction of mouse lymphoma cells. CAD is a protein of 343 amino acids which carries a nuclear-localization signal; ICAD exists in a long and a short form. Recombinant ICAD specifically inhibits CAD-induced degradation of nuclear DNA and its DNase activity. When CAD is expressed with ICAD in COS cells or in a cell-free system, CAD is produced as a complex with ICAD: treatment with caspase 3 releases the DNase activity which causes DNA fragmentation in nuclei. ICAD therefore seems to function as a chaperone for CAD during its synthesis, remaining complexed with CAD to inhibit its DNase activity; caspases activated by apoptotic stimuli then cleave ICAD, allowing CAD to enter the nucleus and degrade chromosomal DNA.
\end{abstract}

Surplus cells are removed by apoptosis ${ }^{1}$ during mammalian development, and when cytotoxic T cells or natural killer cells kill virally infected or tumour cells, the effector cells induce apoptosis in the target cells ${ }^{2}$. Apoptotic cell death is characterized by accompanying morphological changes, such as cell shrinkage, condensation of nuclei, and loss of microvilli ${ }^{3}$. The biochemical hallmark of apoptosis is the cleavage of chromosomal DNA into nucleosomal units, which appears to be the final blow in the cell death process ${ }^{4-6}$. Until now, none of the nuclease(s) responsible for DNA degradation in apoptosis had been identified, although various nucleases such as DNase I, DNase II, and cyclophilins have been proposed as candidates $^{7-9}$

Fas ligand, a member of the tumour-necrosis factor family, is expressed in activated $\mathrm{T}$ cells and natural killer cells, and induces apoptosis in target cells by binding to Fas, its receptor ${ }^{2,10}$. As this process occurs in the presence of inhibitors of protein or RNA synthesis $^{11}$, and even in enucleated cells ${ }^{12}$, all the signalling components necessary for apoptosis may already be present in growing cells, and the apoptotic signals may only trigger them. It has been shown that Fas engagement activates a cascade of caspase proteases $^{13-18}$, as found in most apoptotic processes ${ }^{19}$. Caspases are synthesized as precursor forms, and an apoptotic signal converts the precursors to mature enzymes, which subsequently cleave other caspases that are downstream in the cascade ${ }^{2,20}$. Caspases activated by apoptotic signals cleave various cellular substrates such as actin, poly(ADP-ribose) polymerase, fodrin and lamin, which may be responsible for the morphological changes that occur in the cells ${ }^{21}$.

Fas-induced apoptotis also causes DNA degradation ${ }^{11}$. The cytosolic fraction from Fas-engaged apoptotic cells contain a factor(s) that induces DNA degradation in isolated nuclei, suggesting that a nuclease or its activating molecule(s) is generated in cells during Fas-induced apoptosis ${ }^{22,23}$. The cytosolic extracts from living cells do not cause DNA degradation in nuclei, but treatment of the extracts with caspase 3 converts them to apoptosis-inducing extracts, suggesting that living cells carry a proform of the molecule(s) that induces DNA degradation ${ }^{14}$. We have now purified a protein that can cause DNA degradation in nuclei after treatment with caspase 3.
As this protein has an intrinsic DNase activity, it was designated CAD, for caspase-activated DNase. We also tested for the presence of an inhibitor(s) of DNA degradation and found that the cytosolic fraction from growing, but not from apoptotic, cells contains such an inhibitor (ICAD, for inhibitor of CAD). ICAD was also purified from a mouse T-cell lymphoma. Molecular cloning of mouse CAD complementary DNA revealed that CAD is a protein consisting of 343 amino acids, carrying a nuclear-localization signal at its carboxy terminus. Two different ICAD cDNAs were isolated which coded for a long and a short form; a recombinant ICAD produced in Escherichia coli specifically inhibited the DNase activity of CAD, but did not inhibit DNase I or DNase II. Functional CAD protein was produced in COS cells in the presence of ICAD in a cell-free system, CAD was only found in complex with ICAD. These results indicate that CAD exists as an inactive complex with ICAD in living cells. Caspases activated by apoptotic signals cleave ICAD to release CAD, which then enters the nucleus to degrade chromosomal DNA. This mechanism of activation of this apoptotic DNase is remarkably similar to that used to activate the transcription factor NF-кB.

\section{Identification of CAD and ICAD}

We have previously shown that growing cells contain a factor(s) that can be converted by caspase 3 to a form that causes DNA degradation ${ }^{14}$. To characterize this factor, the S-100 fraction from mouse T-cell lymphoma was fractionated by DEAE-Sepharose column chromatography. Each fraction was treated with caspase 3 , then its ability to cause DNA degradation in nuclei was assayed. As shown in Fig. 1a, the DNA degradation activity eluted as a single peak at about $145 \mathrm{mM} \mathrm{NaCl}$. The activity was not detected without caspase-3 treatment (data not shown). This DNA-degrading activity cleaved naked DNA when plasmid DNA was used as substrate (middle panel, Fig. 1a), and caspase-3-dependent (bottom panel). The S-100 fraction from growing cells was found to inhibit the CAD activity present in lysates from Fas-activated cells. To characterize this CAD-inhibitory activity, we assayed CAD activity in Fasactivated cells in the presence of fractions from the DEAE-Sepharose column. As shown in Fig. 1b, proteins eluting at $170 \mathrm{mM} \mathrm{NaCl}$ inhibited CAD-induced DNA fragmentation in nuclei, indicating 
that growing cells carry a latent form of CAD and its inhibitor (ICAD) in the cytoplasm.

\section{Purification and properties of ICAD}

ICAD was purified by ammonium sulphate fractionation and column chromatography on butyl-Sepharose and phenyl-Superose. When the sample was loaded onto a gel-filtration column, ICAD eluted as a single peak with an apparent relative molecular mass $\left(M_{\mathrm{r}}\right)$ of $75 \mathrm{~K}$. Physical chemical characterization of partially purified ICAD indicated that it is resistant to heat $\left(90^{\circ} \mathrm{C}\right)$ and denaturant $(0.1 \%$ SDS $)$. We therefore heated proteins in each fraction from the gel filtration column at $90^{\circ} \mathrm{C}$ for $15 \mathrm{~min}$ and centrifuged them. The supernatants gave a few bands on SDSpolyacrylamide gel electrophoresis (Fig. 2a) and had ICAD activity (Fig. 2b). To assign ICAD to a specific band, the gel was cut into slices for elution: an eluted $32 \mathrm{~K}$ protein was found to inhibit CADinduced DNA degradation in nuclei (Fig. 2c) and its DNase activity (Fig. 2d), indicating that the $32 \mathrm{~K}$ protein is ICAD; the native form of ICAD is presumably a homodimer, because it behaves as a $75 \mathrm{~K}$ protein on gel-filtration column chromatography. The overall purification of ICAD from the S-100 fraction was $\sim 17,000$-fold, with a yield of $11.8 \%$ (Table 1 ).

Purified ICAD was sequenced and five peptide sequences were obtained. One was found in the mouse EST databases and, using this sequence, two different ICAD cDNAs (ICAD-L and ICAD-S) were isolated from a mouse T-cell lymphoma cDNA library. These cDNAs contained open reading frames of 331 and 265 amino acids, respectively (Fig. 3a). The two cDNAs were identical up to aminoacid position 261, after which the sequences differed, suggesting that the ICAD-L and ICAD-S messenger RNAs are generated through alternative splicing. All five peptide sequences obtained with the purified ICAD were found in the ICAD-S sequence, and its calculated $M_{\mathrm{r}}(29.169 \mathrm{~K})$ agreed well with that estimated from SDS-polyacrylamide gel electrophoresis. Both ICAD-L and ICAD$S$ are rich in acidic amino acids, and have isoelectric points of $\sim 4.5$. A BLAST homology search in GenBank databases indicated that mouse ICAD-L is highly homologous to human DFF45 (DNAfragmentation factor 45$)^{24}$. As shown in Fig. 3b, the two sequences are $76.1 \%$ identical, indicating that mouse ICAD-L could be a counterpart of human DFF45.

To test the enzymatic properties of ICAD, ICAD-L and ICAD-S were prepared as glutathione- $S$-transferase (GST) fusion proteins in E. coli. As shown in Fig. 4a, recombinant ICAD inhibited the DNA degradation in nuclei induced by lysate from Fas-activated cells. This inhibition by ICAD was dose-dependent: a few ng of ICAD-L were sufficient to inhibit CAD activity in $20 \mu \mathrm{g}$ lysate from Fasactivated cells. ICAD-L also efficiently inhibited the DNase activity of CAD (Fig. 4b), but it did not inhibit either DNase I or DNase II (Fig. 4c, d). A similarly specific inhibition against CAD was observed with ICAD-S (data not shown).

\section{Purification and cloning of CAD}

Loss-of-function mutations of the Fas gene cause lymphadenopathy and splenomegaly ${ }^{2}$. As cytosolic extracts from the lymph nodes of one such mouse mutant, MRL-lpr, have a high level of CAD activity, we used them as starting material for purification of CAD. We have noticed that CAD self-activated during purification and that this activated form is unstable. The S-100 fraction was therefore first treated with an inhibitor of caspase 3 (bio-DEVD-cmk) ${ }^{14}$, CAD was then purified by ammonium sulphate fractionation and chromatography on heparin-agarose, resource- $Q$ and resource-S columns. CAD activity was assayed by its ability to induce DNA degradation in intact nuclei or by its DNase activity on plasmid DNA. The crude extracts (S-100) contained constitutively active DNase activity, which was mostly removed by resource-Q column chromatography. After this stage, the caspase-activated DNase activity copurified with the DNA-fragmentation activity in intact nuclei.
As already described, ICAD is a mouse homologue of human DFF45. Caspase 3 cleaves DFF45/ICAD ${ }^{24,25}$, so we considered that CAD could be bound to ICAD as a complex. We therefore biotinylated the partially purified CAD (resource-S fraction), and treated it with caspase 3 , then loaded it onto an affinity column of GST-DFF45. When the bound proteins were eluted from the column with glutathione, western blot analysis of the eluates with horseradish peroxidase-conjugated streptavidin revealed a specific band of $M_{\mathrm{r}} 40 \mathrm{~K}$ in the eluate from the GST-DFF45 affinity column, but not in eluate from the control column (GST-revDFF45) (Fig. 5a). When the sample was loaded onto the DFF45 affinity column without caspase 3 treatment, the $40 \mathrm{~K}$ protein was not retained on the column. These results indicated that the $40 \mathrm{~K}$ protein was probably CAD, and that it can bind to human DFF45 or ICAD. The inability of the inactive form of CAD to bind to the affinity column suggested that this form could be a complex of CAD and ICAD, and that treatment with caspase releases CAD from ICAD. As GST-DFF45 carries a thrombin cleavage site ${ }^{26}$ and DFF45 can be cleaved by caspase 3 (ref. 24), we treated the column with thrombin and caspase 3 and eluted a $40 \mathrm{~K}$ protein (data not shown, and Fig. 5b). The size of this protein was identical to that eluted by glutathione, suggesting that the protein is not cleaved by caspase 3 . No potential cleavage site for caspase 3 was found in the primary sequence of CAD (Fig. 5d).

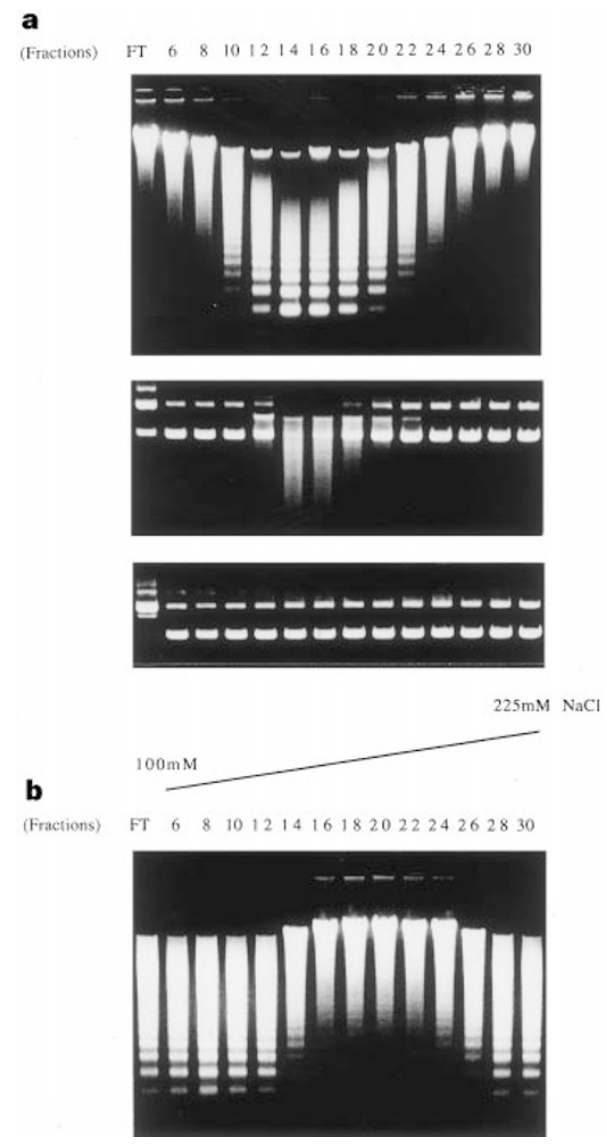

Figure 1 CAD and ICAD activity in extracts from mouse WR19L cells. The S-100 fraction (500 mg protein) from WR19L cells was loaded onto a DEAE-Sepharose column $(2.6 \times 11 \mathrm{~cm})$, and proteins were eluted with a $50-350 \mathrm{mM} \mathrm{NaCl}$ linear gradient. a, Aliquots $(10 \mu \mathrm{l})$ of the indicated fractions were treated with caspase 3 , and CAD activity on nuclear (top) or plasmid DNA (middle) determined. DNase activity was also determined without caspase 3 treatment (bottom). b. Using 10- $\mu$ l aliquots, ICAD activity in the indicated fractions was determined using lysates from Fas-activated W4 cells and mouse liver nuclei. FT, flow through. 
To prepare enough purified CAD for protein-sequence analysis, $2 \mathrm{mg}$ of the resource-S fraction was activated with caspase 3 and loaded onto the GST-DFF45 affinity column. As the elution with a combination of caspase 3 and thrombin is more efficient than with glutathione, the column was treated with thrombin and caspase 3 . Analysis of the eluate by silver staining (Fig. 5b) revealed a band at $M_{\mathrm{r}} 40 \mathrm{~K}$. Several intense bands smaller than $35 \mathrm{~K}$ were obtained after thrombin and caspase- 3 treatment. The eluate from the affinity column had strong CAD activity. As shown in Fig. 5c, one microlitre of the eluate, which contained less than $1 \mathrm{ng}$ of the $40 \mathrm{~K}$ protein, completely fragmented nuclear DNA within 2 hours and also digested plasmid DNA. If CAD was loaded onto the affinity column without pretreatment with caspase 3, there was no $40 \mathrm{~K}$ protein or CAD activity in the eluate (Fig. 5b, c). We concluded that the $40 \mathrm{~K}$ protein is CAD. A summary of the purification is shown in Table 2: CAD-induced DNA degradation in nuclei was assayed by measuring the amount of histone/DNA complex released from the nuclei. The overall purification of CAD was $\sim 180,000$-fold, with a yield of $2.3 \%$.

Five peptide-fragment sequences of the putative CAD protein were obtained, two of which were used to design the degenerate oligonucleotide primers for polymerase chain reaction (PCR) amplification from a mouse T-cell cDNA library. A fragment of 332 base pairs (bp) was obtained and used as a probe to screen the cDNA library by colony hybridization. One of the positive clones carrying the full-length coding sequence was characterized by nucleotide-sequence analysis. The cDNA (pEF-CAD) contained an open reading frame of 345 amino acids (Fig. 5d). All five peptide sequences obtained from the purified protein could be found in the coding sequence. The amino terminus of the purified CAD was identified as alanine, which appeared at the third position of the coding sequence, suggesting that mouse CAD can undergo posttranslational processing at the $\mathrm{N}$ terminus. Extra methionine and cysteine residues preceding the $\mathrm{N}$ terminus of the mature protein have also been found in actin from various species ${ }^{27}$. Mature CAD consists of 343 amino acids, with a calculated $M_{\mathrm{r}}$ of $39.333 \mathrm{~K}$. Mouse $\mathrm{CAD}$ is rich in cysteine residues (12 residues in the mature protein) and is a basic protein with an isoelectric point of 9.7. A BLAST search of the GenBank databases did not reveal any genes homologous to the $\mathrm{CAD}$ gene, so $\mathrm{CAD}$ is a previously undiscovered gene product. However, the sequence at the $\mathrm{C}$ terminus consisting of 15 amino acid residues has the features of a nuclear-localization

\begin{tabular}{|c|c|c|c|c|c|}
\hline Step & $\begin{array}{l}\text { Protein } \\
\text { (mg) }\end{array}$ & $\begin{array}{l}\text { Total activity } \\
(\times 1,000 \text { units })\end{array}$ & $\begin{array}{l}\text { Specific activity } \\
\quad\left(\text { units } \mu \mathrm{g}^{-1}\right)\end{array}$ & $\begin{array}{l}\text { Purification } \\
\text { (fold) }\end{array}$ & Yield (\%) \\
\hline S-100 & $1,710.0$ & $20,853.0$ & 12.2 & & 100 \\
\hline DEAE-Sepharose & 125.0 & $10,975.6$ & 87.8 & 7 & 52.6 \\
\hline Ammonium sulphate & 62.0 & $10,812.1$ & 174.3 & 14 & 51.8 \\
\hline Butyl-Superose & 4.2 & $3,995.1$ & 951.6 & 78 & 19.2 \\
\hline Phenyl-Sepharose & 1.3 & $3,408.5$ & $2,622.0$ & 215 & 16.3 \\
\hline Superdex-200 & 0.12 & $2,726.3$ & $22,719.5$ & 1,863 & 13.1 \\
\hline Heat treatment & 0.012 & $2,453.7$ & $204,475.6$ & 16,767 & 11.8 \\
\hline
\end{tabular}

The S-100 fraction was prepared from $4 \times 10^{11}$ mouse WR19L cells. ICAD activity was determined with mouse nuclei as described in Methods. One unit of inhibitory activity was defined as the dilution that inhibits half of one unit of CAD activity. The protein concentration of ICAD in the heat-treated sample was estimated from silver staining on SDS-polyacrylamide gel eletrophoresis.

a

(Fractions) M 1213141516171819 $M_{\mathrm{r}}(\mathrm{K}) 220^{-}$

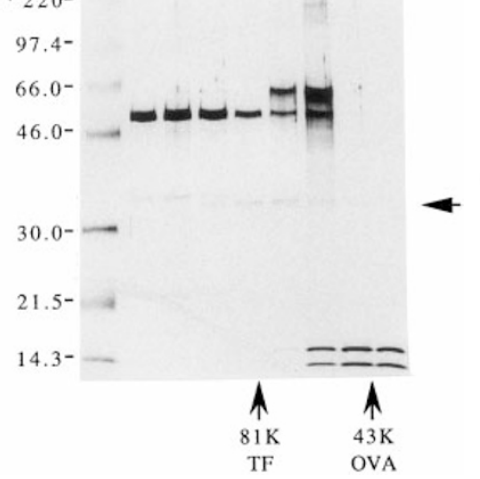

b
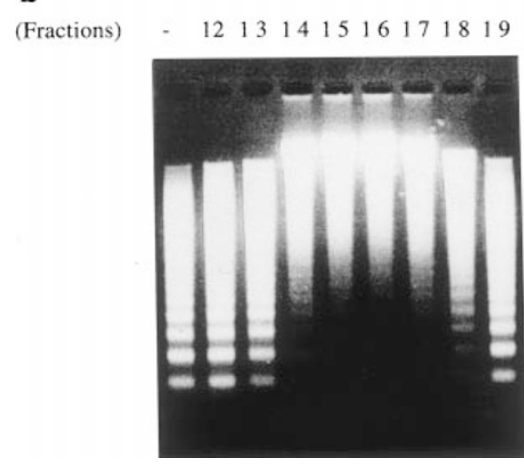

c (Gel slice)

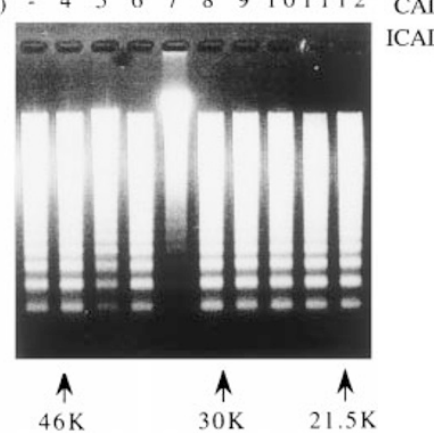

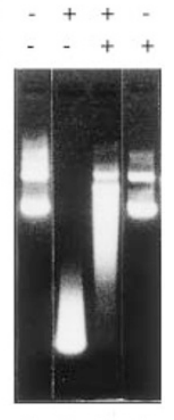

$\begin{array}{llll}1 & 2 & 3 & 4\end{array}$
Figure 2 Identification of ICAD. Fractions (1.3 mg protein) from a phenylsuperose column were loaded onto a Superdex-200 column. Fractions were heated and insoluble proteins removed. a, Aliquots $(5 \mu \mathrm{l})$ of the indicated fractions were electrophoresed on a $10-20 \%$ gradient polyacrylamide gel and proteins were visualized by silver staining. Migration of marker proteins (Amersham) are shown on the left. The Superdex-200 column was calibrated by using the standard proteins transferrin (TF, 81K) and ovalbumin (OVA, 43K); their elution positions are indicated. ICAD is indicated by the arrow on the right. $\mathbf{b}$, Using $5-\mu \mid$ aliquots of the indicated fractions, ICAD activity was determined. CAD activity without ICAD is shown in the first lane (-). c, Fractions 14-17 from the Superdex200 column were pooled, concentrated, and heated. After centrifugation, 100 ng protein in the supernatant was separated by electrophoresis on a 10-20\% gradient polyacrylamide gel. After slicing up the gel, proteins were eluted and precipitated in cold acetone as described ${ }^{44}$, then dissolved in buffer D containing $6 \mathrm{M}$ guanidine- $\mathrm{HCl}$. The solution was incubated at room temperature for $20 \mathrm{~min}$ and dialysed at room temperature against buffer D. Using $5-\mu$ l aliquots, ICAD activity was determined. The first lane (-) shows CAD activity without ICAD. d, Aliquot $(5 \mu \mathrm{l})$ of the protein eluate from gel slice 7 in $\mathbf{c}$ was incubated at $4^{\circ} \mathrm{C}$ for 30 min with the lysate from Fas-activated W4 cells $(20 \mu \mathrm{g})$, and the remaining CAD activity was determined with plasmid DNA. Lane 1, plasmid DNA; lane 2, DNA incubated with CAD; lane 3, DNA incubated with CAD and ICAD; lane 4, DNA incubated with ICAD. 
signal $^{28}$, which is in agreement with the ability of CAD to enter the nucleus to degrade DNA.

\section{Expression of CAD in vitro}

To confirm that our cloned CAD cDNA encodes the protein with CAD activity, a CAD-expression plasmid (pEF-CAD) was introduced into COS cells and cell lysates prepared. As shown in Fig. 6a, untreated lysates did not induce DNA degradation, but when treated with caspase 3 , the lysates had CAD activity that was slightly higher (4-fold) than that of empty-vector-transfected cells. As this expression of CAD was low, we considered that either functional CAD could not be synthesized in the absence of ICAD, or that the transfected cells were immediately killed by CAD. To test these possibilities, we introduced the CAD expression plasmid into COS cells together with the expression plasmid for ICAD. Expression of ICAD alone in COS cells inhibited endogenous CAD, and the lysates

\section{a}

MICAD-S : MELLSRGASAPDPDDVRPLKPCLLRRNHSRDQHGVAASSLEELRSKACELE MICAD-L: $75 \quad 100$ mICAD-S: AIDKSLTPITLVLAEDGTIVDDDDYFLCLPSNTKFVALACNEKWTYNDSD mICAD-L: mICAD-S: GGTAWVSQESFEADEPDSRAGVKWKNVARQLKEDLSSIILLSEEDLQALI MICAD-L : - - - - MICAD-S: DIPCAELAQELCQSCATVQGLQSTLQQVLDQREEARQSKQLLELYLQALE mICAD-L: MICAD-L : mICAD-S: KEGNILSNOKESKAALSEELDAVDTGVGREMASEVLLRSQILTTLKEKPA

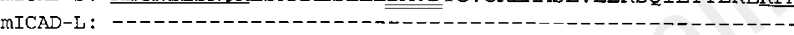

MICAD-S: PELSLSSODLEVGKN

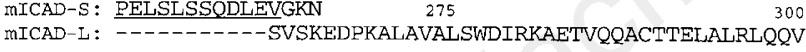

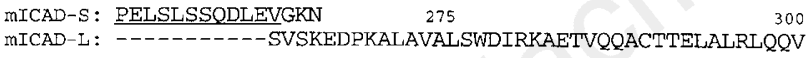
MICAD-L : QSLHSLRNLSARRSPLPGEPQRPKRAKRDSS

Figure 3 Comparison of amino-acid sequences of mouse ICAD-S and ICAD-L and of mouse ICAD-L and human DFF-45. a, The amino-acid residues in ICAD- $L$ that are identical to those of ICAD-S are indicated by a dash. The five peptide sequences obtained from purified ICAD are underlined. Two putative cleavage had no CAD activity even after treatment with caspase 3 . But when CAD was co-expressed with ICAD, the lysates had strong CAD activity. As shown in Fig. 6b, 10-20 ng of total lysate from cells cotransfected with CAD and ICAD efficiently cleaved chromosomal DNA in nuclei and digested plasmid DNA when treated with caspase 3. CAD activity in the transfected cells was $\sim 1,000$ times higher than in control cells transfected with empty vector, indicating that our cloned cDNA codes for functional CAD.

To investigate the role of ICAD in the expression of CAD, we synthesized CAD in a cell-free system. Specifically, CAD mRNA was synthesized with $\mathrm{T} 7$ polymerase and translated in reticulocyte lysates in the presence or absence of recombinant GST-ICAD. In both cases, CAD was synthesized as a $40 \mathrm{~K}$ protein (Fig. 7a). CAD made in the absence of ICAD was inactive but was fully functional when synthesized in the presence of ICAD and activated by caspase 3 (Fig. 7b). When ICAD was added to the reaction after CAD

\section{b}

mICADL: MELSRGASAPDPDDVRPLKPCLIIRRNHSRDQHGVAASSLEEIRSRACEII hDFF-45: MEVTGDAGVPESGEIRTLKPCLLRRNYSREQHGVAASCLEDIRSKACDIL

$$
75 \quad 100
$$

MICADL: AIDKSLTPITLVIAADGTIVDDDDYFLCLPSNTKFVALACNEKWTYNDSD hDFF-45: AIDKSITPVTLVIAEDGTIVDDDDYFLCLPSNIKFVAIASNEKWAYNNSD

$125 \quad 150$ hDFF-45: GGTAWI SQESFDVDETDSGAGLKWKNVARQLKEDLSSIILLSEWDIQMLV

mICADL : DIPCAELAQELCQSCATVQGLQSTIOQVIDQREEARQSKQLLELYLQAIE ADFF-45: DAPCSDLAOELROSCATVORLOHTLOOVIDORFEVROSKOLIOLYTOAL

$$
225
$$

mICADL: KEGNILSNQKESKAALSEELDAVDTGVGREMASEVLIRSQIITTLKERPA hDFF-45: KEGSLLSKQEESKAAFGEEVDAVDTGISRETSSDVALASHILTALREKQA

$$
275
$$

MICADL: PELSLSSODIESVSKFDPRATAVATSHDIRKAETVOOACTTELATRLOQV hDFF-45: PELSLSSQDIELVTKEDPKALAVALNWDIKKTETVQEACERELAIRIQQT

mICADL: QSLHSLRNLSARRSPLPGEPQRPKRAKRDSS

hDFF-45: QSLHSLRS ISASKASPPGDLQNPKRARQDPT

sites for caspase 3 are indicated by double underlines. The amino-acid number is shown above the sequence. $\mathbf{b}$, Alignment of amino-acid sequences of mouse ICAD-L and human DFF45. The amino-acid sequence of human DFF45 (ref. 24) was aligned with that of mouse ICAD-L. Identical amino acids are in bold.
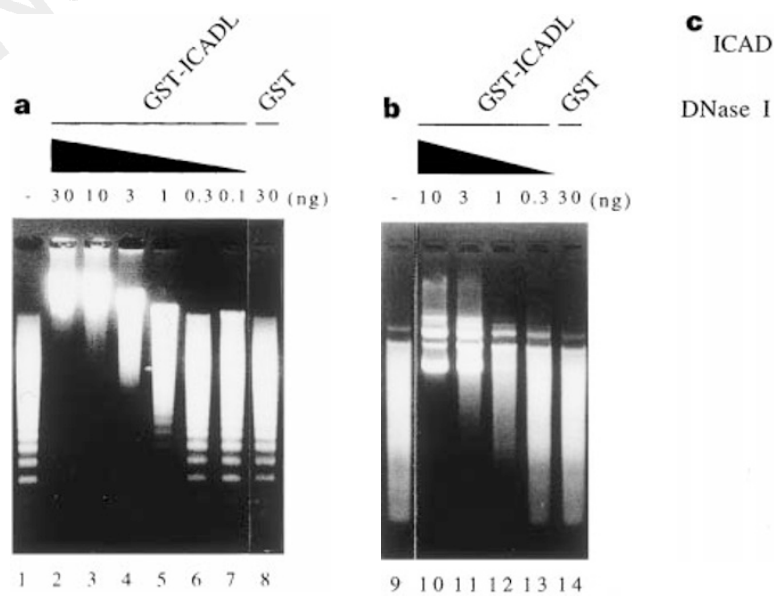

Figure 4 Specific inhibition of CAD activity by recombinant ICAD. $\mathbf{a}$ and $\mathbf{b}$, Cell lysate from Fas-activated W4 cells $(20 \mu \mathrm{g})$ was preincubated with the indicated amounts of GST-ICAD-L, and the CAD activity was determined with $\mathbf{a}$, liver nuclei, b, or plasmid DNA. The activity of CAD without preincubation with GST-ICAD-L is shown in lanes 1 and 9. The effect of the control GST protein on CAD activity is
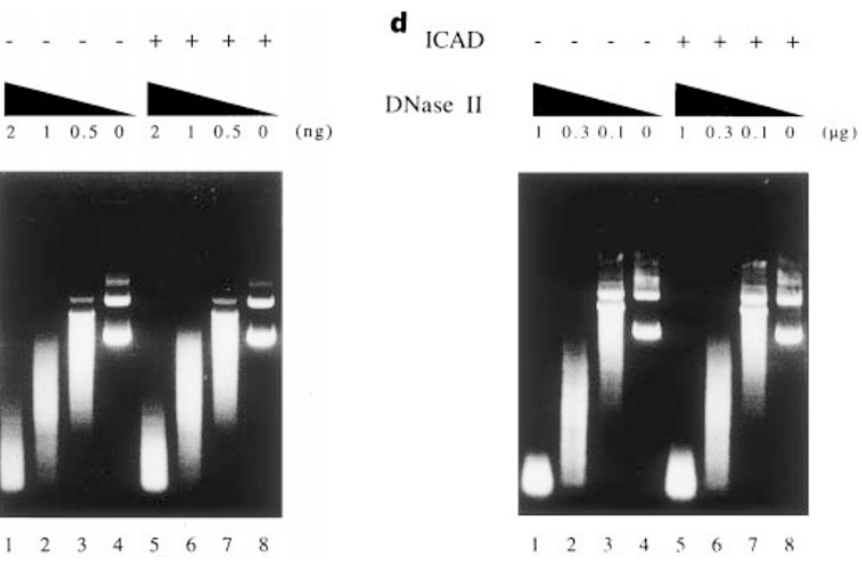

shown in lanes 8 and 14. c, d, Increasing amounts of DNase I (c) or DNase II (d) were preincubated at $4^{\circ} \mathrm{C}$ for $30 \mathrm{~min}$ with $10 \mathrm{ng}(\mathbf{c})$ or $10 \mu \mathrm{g}(\mathbf{d})$ of GST-ICAD-L. Plasmid DNA $(1.0 \mu \mathrm{g})$ was added and the incubation continued at $30^{\circ} \mathrm{C}$ for $2 \mathrm{~h}$, then analysed by agarose gel electrophoresis. Lanes 1-4, DNase alone; 5-8, DNase with ICAD-L. 
synthesis, however, no CAD activity was detected (data not shown). These results indicate that functional CAD can only be synthesized in the presence of ICAD, and suggest that newly synthesized CAD is complexed with ICAD. When ICAD tagged with Flag epitope was immunoprecipitated with anti-Flag antibody, the $40 \mathrm{~K}$ CAD protein coimmunoprecipitated with ICAD (data not shown); treatment of the precipitate with caspase 3 gave full CAD activity (Fig. 7c), confirming that CAD is a DNase that forms a complex with ICAD and is activated by caspase 3 .

\section{Discussion}

Ever since the discovery that DNA fragmentation occurs during apoptosis ${ }^{6}$, the identity of the DNase responsible has been sought. However, this DNase was labile and scanty, making purification of this enzyme difficult ${ }^{29}$. Several enzymes have been proposed as candidates, including DNase I, DNase II, cyclophilins, and DNase- $\gamma$ (refs 7-9, 30), but none of these fulfilled all the criteria for the apoptotic DNase. CAD is a DNase with a high specific activity, comparable to or higher than that of DNase I and DNase II, which can be generated from cell extracts by treatment with caspase 3 , and we have also identified its specific inhibitor, ICAD. By using recombinant $\mathrm{CAD}$ produced in COS cells, we have shown that
CAD's DNase activity can be inhibited by aurintricarboxylic acid at $30 \mu \mathrm{M}$ (M.E. and S.N., unpublished data), a concentration that inhibits DNA degradation in most apoptotic cells ${ }^{31,32}$. Northern blot analysis indicates that CAD and ICAD mRNAs are ubiquitously expressed in various tissues (data not shown). The amino-acid sequence of CAD contains a nuclear-localization signal. Furthermore, overexpression of ICAD blocks DNA degradation induced by Fas engagement or by treatment with staurosporine ${ }^{25}$. These results indicate that CAD is the DNase responsible for DNA degradation during apoptosis, although we cannot rule out the possibility that other DNases may be involved in some circumstances.

The inactive form of CAD in non-apoptotic growing cells seems to exist as a complex of CAD with ICAD, because the caspaseactivated but not the inactive form of CAD could bind free ICAD, and because CAD synthesized in a cell-free system was recovered as a complex with ICAD. When partially purified CAD (resource-S fractions) was heated to inactivate CAD, the ICAD activity was found in the fractions that contained CAD (data not shown). CAD is a basic protein $(\mathrm{p} I 9.7)$, whereas ICAD is an acidic protein $(\mathrm{pI} 4.5)$, so these proteins may interact electrostatically. Caspase 3 is activated during apoptosis ${ }^{14,19}$ and cleaves $\mathrm{ICAD}^{25}$, which probably releases CAD from ICAD. When we analysed the inactive and

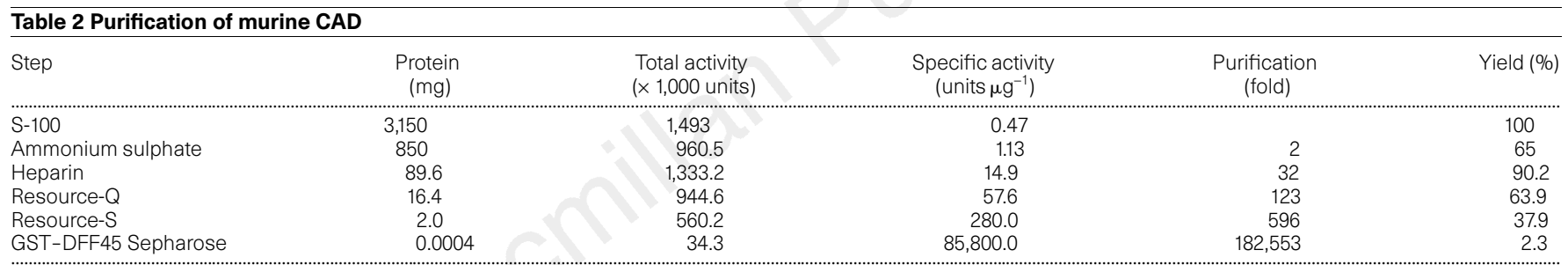

The S-100 fraction was prepared from lymph nodes of $14 \mathrm{MRL}-1 \mathrm{pr} / \mathrm{lpr}$ mice. To determine CAD activity, $2 \times 10^{5}$ nuclei were incubated with the sample at $30^{\circ} \mathrm{C}$ for $2 \mathrm{~h}$ in $20 \mu \mathrm{l}$ of buffer $\mathrm{A}$ containing $150 \mathrm{ng}$ caspase 3 . The histone/DNA complex released from nuclei was assayed with a cell death ELISA kit (Boehringer Mannheim). One unit of CAD activity ws arbitrarily defined as the activity that gives one optical density unit at $405 \mathrm{~nm}$ in the ELISA system. Ten units of this assay roughly correspond to the activity that degrades $1 \mu \mathrm{g}$ plasmid DNA at $30^{\circ} \mathrm{C}$ for $2 \mathrm{~h}$. The protein concentration of CAD in the eluate from GST-DFF45 Sepharose was estimated from silver staining after SDS-PAGE.
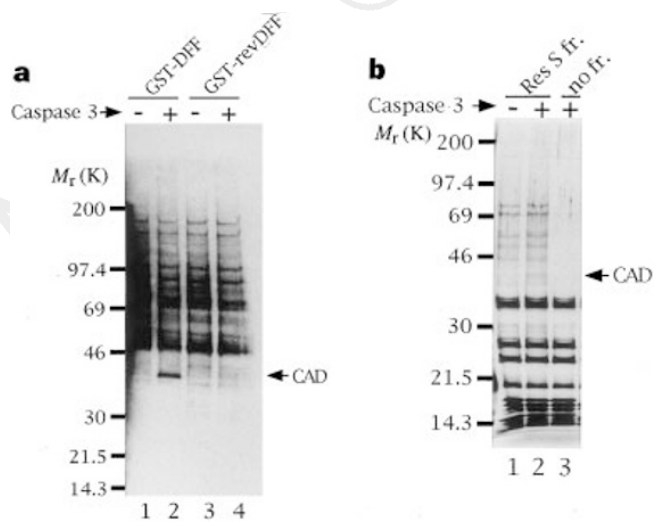

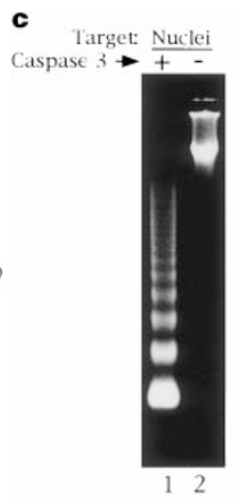

Figure 5 Identification and amino-acid sequence of CAD. a, Partially purified CAD (resource-S fraction, $0.1 \mathrm{mg}$ ) was biotinylated with biotin- $N$-hydroxysuccinimide ester (Pierce) and treated at $4^{\circ} \mathrm{C}$ overnight with (lanes 2 and 4 ) or without (lanes 1 and 3) $6 \mu \mathrm{g} \mathrm{ml}^{-1}$ caspase 3 , then the caspase was inactivated with bio-DEVD-cmk. The sample ( $16 \mu \mathrm{g}$ protein) was loaded onto GST-DFF45 affinity beads ( $10 \mu \mathrm{l}$ bed volume) (lanes 1 and 2) or control GST-revDFF beads (lanes 3 and 4). The beads were incubated at $4^{\circ} \mathrm{C}$ for $2 \mathrm{~h}$ with $20 \mu \mathrm{l}$ buffer $\mathrm{G}$ containing $5 \mathrm{mM}$ glutathione. Proteins released from the beads were analysed by western blotting with horseradish-peroxidase-conjugated streptavidin and the biotin-streptavidin complex was visualized by an enhanced chemiluminescence system (Renaissance; Dupont NEN). b. The resource-S fraction (2 mg protein each) was incubated at $4^{\circ} \mathrm{C}$ overnight with (lane 2) or without (lane 1) caspase 3. After inactivating caspase 3 with bio-DEVD-cmk, samples were applied to the GST-DFF45 affinity

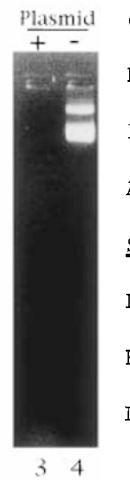

MCAVLROPKCVKLRALHSACKFGVA TARARCQELLRKGCVRFQLPMPGFPAV 75
PVRRWHGGDGRLLPGPFPTTLSSYCFTAGETWHGYVSDITRFLSVFNEPH AGVIQAARQLLSDEQAPLRQKLLADLLHHVSONITAETREQDPSWFEGLE SRFRNKSGYLRYSCESRIRGYLREVSAYTSMVDEAAQEEYLRVLGSMCQK LKSVQYNGSYFDRGAEASSRLCTPEGWFSCQGPFDLESCLSKHSINPYGN RESRILFSTWNLDHI IEKKRTVVPTLAEAIQDGREVNWEYFYSLLFTAEN 325 LKLVHIACHKKTTHKLECDRSRIYRPQTGSRRKOPARKKRPARKR ${ }^{*}$

column. $5 \mu \mathrm{l}$ of fractions $(100 \mu \mathrm{l})$ from the affinity column was analysed by electrophoresis on a polyacrylamide gel, and proteins were visualized by silverstaining. Buffer G was subjected to the same procedure; that is, binding to GSTDFF45 affinity column and elution with caspase 3 and thrombin (lane 3 ). Caspase 3 and thrombin are mostly seen in this lane. c, CAD activity in $1-\mu$ l aliquots of fractions $(100 \mu l)$ from the affinity column $(\mathbf{b})$ was determined with mouse liver nuclei (lanes 1 and 2) or with plasmid DNA (lanes 3 and 4). Lanes 1 and 3, caspase-3-treated sample loaded onto GST-DFF45 affinity column. Lanes 2 and 4 , samples loaded on the affinity column without caspase 3 treatment. d, Aminoacid sequence of mouse CAD predicted from the cDNA sequence. The $N$ terminus of purified CAD starts with Ala-3. Five peptide sequences obtained from purified $C A D$ are underlined. A putative nuclear-localization signal at the $\mathrm{C}$ terminus is indicated by a double underline. 


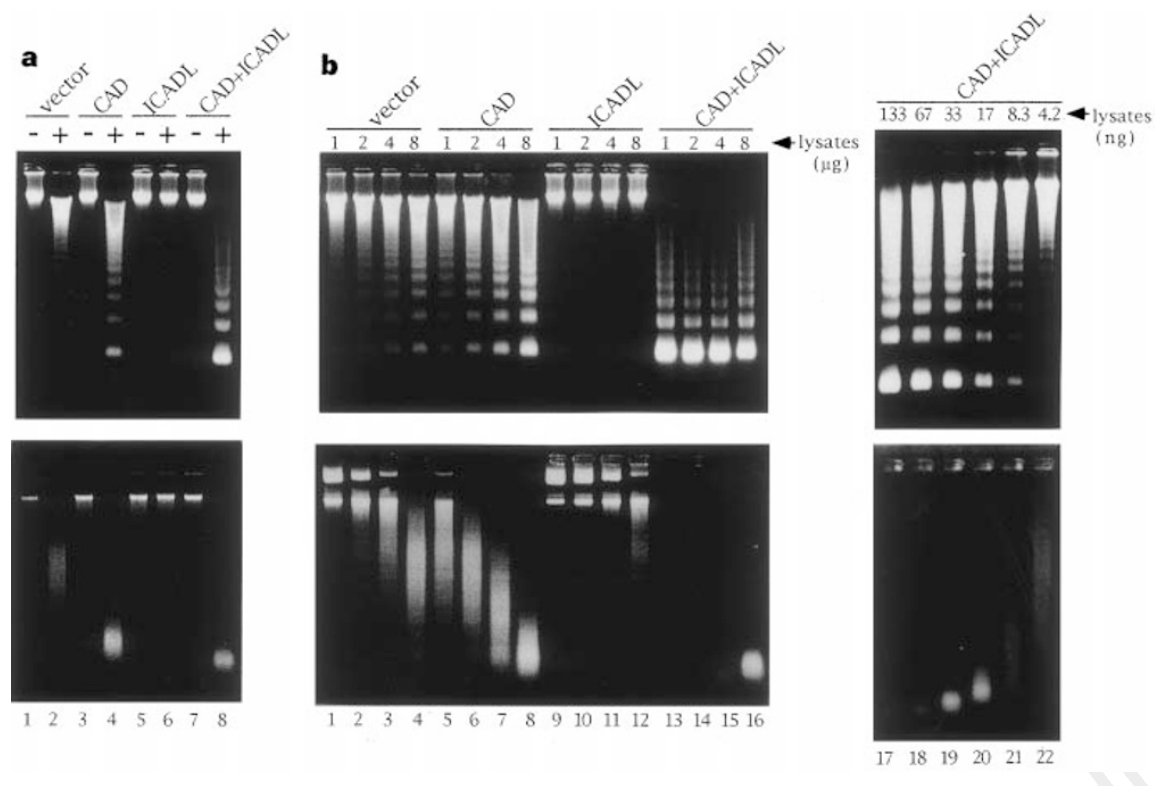

Figure 6 Expression of mouse CAD in COS cells. a, COS cells were transfected with pEF-BOS (lanes 1 and 2), pEF-CAD (lanes 3 and 4), or pEF-ICAD-L (lanes 5 and 6 ), or cotransfected with $\mathrm{pEF-CAD}$ and pEF-ICAD-L (lanes 7 and 8), and cell lysates were prepared as described in Methods. Aliquots of the lysates $(8 \mu \mathrm{g}$ protein) were assayed for CAD activity with nuclei (top) or with plasmid DNA (bottom) in the absence (-) (lanes 1, 3, 5 and 7) or presence (+) (lanes 2, 4, 6 and 8) of caspase 3. b, Cell lysates were prepared from COS cells transfected with pEF-BOS (lanes 1-4), pEF-CAD (lanes 5-8), or pEF-ICAD-L (lanes 9-12), or cotransfected with pEF-CAD and pEF-ICAD-L (lanes 13-22). Aliquots from each lysate were assayed for $C A D$ activity with mouse liver nuclei (top) or with plasmid DNA (bottom) in the presence of caspase 3 .

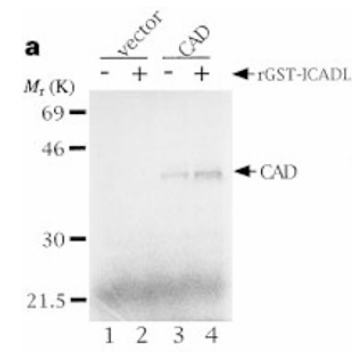

b

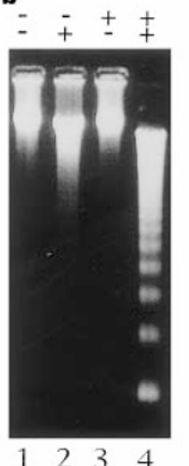

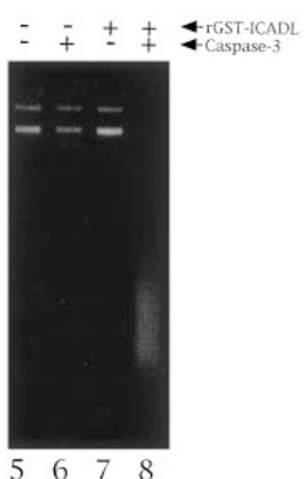

c
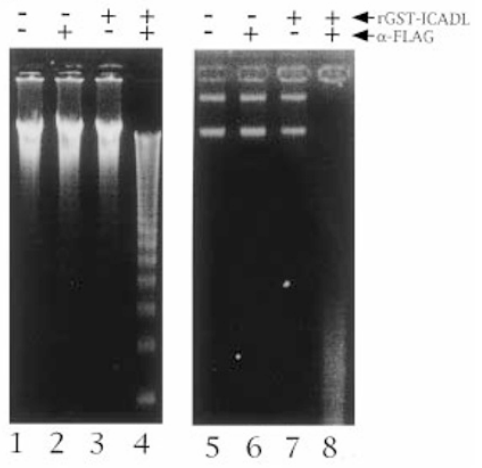

Figure 7 Expression of mouse CAD in a cell-free system, and binding of $C A D$ with ICAD. a, The pcDNA-CAD (lanes 3 and 4 ) or the empty vector (lanes 1 and 2 ) was subjected to the in vitro transcription and translation in the presence of ${ }^{35} \mathrm{~S}$-Met. The reaction mixtures in lanes 2 and 4 included $160 \mathrm{ng}$ of GST-ICAD-L. After reaction, $5-\mu$ l aliquots were analysed by electrophoresis on a polyacrylamide gel and autoradiographed. b. Mouse CAD was synthesized in the in vitro transcription and translation system in the absence (lanes 1,2, 5 and 6) or presence (lanes 3, 4, 7 and 8) of GST-ICAD-L. Using $3 \mu$ l aliquots, CAD activity with

nuclei (lanes 1-4) or plasmid DNA (lanes 5-8) was determined in the absence (lanes 1, 3, 5 and 7) or presence (lanes 2, 4, 6 and 8) of caspase 3. c, Mouse CAD was synthesized in the cell-free system in the absence (lanes 1 and 2) or presence (lanes 3 and 4) of GST-ICAD-L. The ICAD-L was immunoprecipitated with anti-Flag antibody (lanes 2, 4, 6 and 8), or control antibody (lanes 1, 3, 5 and 7) and the precipitates suspended in $10 \mu \mathrm{l}$ buffer $\mathrm{G}$. Using 3- $\mu$ l aliquots, CAD activity with nuclei (lanes 1-4) or plasmid DNA (lanes 5-8) was determined in the presence of caspase 3 .

caspase-3-activated forms of CAD by gel filtration, their apparent $M_{\mathrm{r}}$ values were $80 \mathrm{~K}$ and $40 \mathrm{~K}$, respectively (data not shown). This mechanism for the activation of CAD (Fig. 8) is very similar to that used by the nuclear transcription factor NF- $\kappa \mathrm{B}$ (refs 33,34 ): NF- $\kappa \mathrm{B}$ is kept as a complex with I $\mathrm{B}$ in the cytoplasm until various stimuli activate a kinase cascade which leads to the ubiquitin-dependent degradation of ІкB. The degraded IкB dissociates from NF-кB, which then enters the nucleus to activate or repress the expression of various genes. In the apoptotic pathway, various stimuli, including cytokines, activate a protease cascade of caspases, which could degrade ICAD and cause its dissociation from CAD; CAD could then enter the nucleus to degrade the chromosomal DNA. NF- $\kappa B$ carries a nuclear-localization signal, as does CAD, and one of the roles of I $\kappa \mathrm{B}$ is to mask this signal to prevent NF- $\kappa \mathrm{B}$ from entering the nucleus ${ }^{35}$. ICAD may inhibit not only the DNase activity of $\mathrm{CAD}$, but also its translocation into the nucleus, because most inactive CAD is found in the cytoplasm (data not shown).

Most DNases and proteases are sequestered into lysosomes as soon as they are synthesized. Some proteases, such as caspases in the

cytoplasm, exist in inactive precursor forms which are activated by various stimuli ${ }^{19}$. This $\mathrm{CAD} / \mathrm{ICAD}$ partnership is analogous to that of the bacterial DNases that are encoded by colicin genes and are coordinately expressed with their inhibitors ('immunity proteins'), immediately forming a complex with them ${ }^{36}$. ICAD works as a specific chaperone, allowing the proper folding of the nascent CAD polypeptide. Chaperones are proteins that prevent incorrect association of, within or between polypeptides during de novo protein folding, and also function to guide proteins to cellular organelles while maintaining their unfolded structure ${ }^{37}$. Although most chaperones are multifunctional and ubiquitous, chaperone-like functions have been identified that are specific for the $\beta$-subunit of a potassium channel ${ }^{38}$ and for one of the subunits of the $20 \mathrm{~S}$ proteasome $^{39}$. The subunit of the $20 \mathrm{~S}$ proteasome is synthesized as a precursor which is processed during the assembly of the proteasomes from their subunits. CAD is synthesized with two extra amino acids at its $\mathrm{N}$ terminus, which may be removed by association with ICAD.

Our results described here and in an accompanying Letter ${ }^{25}$ 


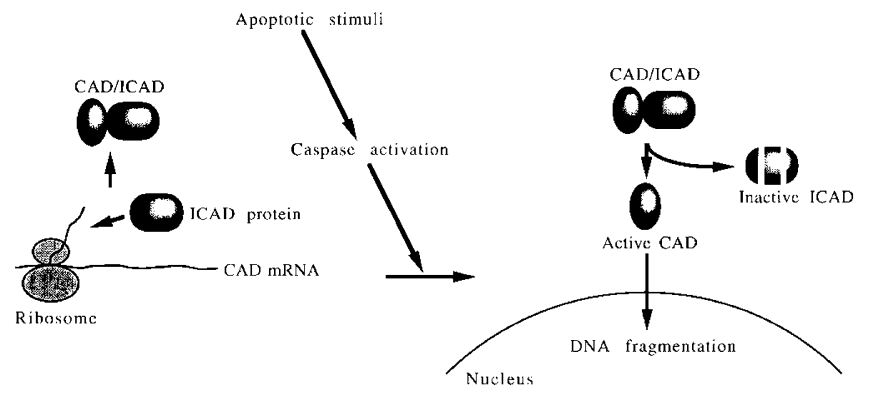

Figure $8 \mathrm{~A}$ model for the function of CAD and ICAD in apoptosis. When CAD protein is synthesized, ICAD may bind to the nascent chain of CAD to allow its correct folding. ICAD remains complexed with CAD to inhibit the DNase activity of CAD and to mask its nuclear-localization signal to keep CAD in the cytoplasm. When apoptotic stimuli activate caspases, ICAD is cleaved and, once released, CAD can enter the nucleus where it degrades chromosomal DNA.

establish CAD as the long-sought-after DNase that cleaves chromosomal DNA during apoptosis. The identification and molecular cloning of CAD and ICAD, which link the apoptotic proteases (caspases) to chromosomal DNA degradation, contribute to our understanding of the apoptotic process that originates at the deathfactor receptors or from the action of anticancer drugs.

\section{Methods}

Assay for CAD and ICAD. CAD activity was determined by DNAfragmentation assay using mouse liver nuclei ${ }^{22}$ or by a DNase activity assay. Nuclei $\left(2 \times 10^{5}\right)$ were incubated at $30^{\circ} \mathrm{C}$ for $2 \mathrm{~h}$ with samples in $20 \mu \mathrm{l}$ buffer $\mathrm{A}$ (10 mM HEPES-KOH, pH 7.0, $50 \mathrm{mM} \mathrm{NaCl}, 20 \%$ (v/v) glycerol, $40 \mathrm{mM} \beta$ -

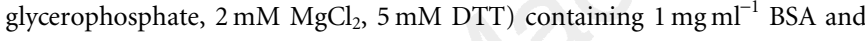
$150 \mathrm{ng}$ caspase 3. DNA was then extracted from the nuclei and analysed by electrophoresis on a $1.5 \%$ agarose gel. In some cases, the released DNA/histone complex was quantified with an ELISA system (kit from Boheringer Mannheim). For DNase assay, nuclei in the mixture were replaced by $1 \mu \mathrm{g}$ plasmid DNA.

ICAD activity was determined by assaying the inhibition of CAD. The cytosolic fraction from Fas-activated cells was used as a source of activated CAD. Mouse W4 cells were treated at $37^{\circ} \mathrm{C}$ for $20 \mathrm{~min}$ with $0.5 \mu \mathrm{g} \mathrm{ml}{ }^{-1}$ anti-Fas $\mathrm{Jo} 2$ antibody $^{40}$, and the S-100 fraction was prepared as described ${ }^{22}$. Caspase 3 was inactivated by incubation of the lysate at $4{ }^{\circ} \mathrm{C}$ for $30 \mathrm{~min}$ with $10 \mu \mathrm{M}$ AcDEVD-cho (Peptide Institute). A test sample was added to the active CAD ( $20 \mu \mathrm{g}$ of cell extract from Fas-activated W4 cells) in a final volume of $20 \mu \mathrm{l}$. After incubation at $4{ }^{\circ} \mathrm{C}$ for $30 \mathrm{~min}$, the remaining CAD activity was determined using nuclei or plasmid DNA as targets, as described.

Recombinant human DFF45 and mouse ICAD. A cDNA coding for human DFF45 (ref. 24) was isolated from a human KT3 cDNA library ${ }^{11}$ by PCR. The PCR product $(1 \mathrm{~kb})$ was fused to the GST gene of pGEX-2T[128/129] ${ }^{26}$ in forward and reverse orientations ( $\mathrm{pGEX}$-DFF and pGEX-revDFF, respectively). The GST-DFF45 fusion protein was expressed in E. coli AD202, and adsorbed to glutathione-sepharose 4B. The beads retained about $1 \mathrm{mg}$ GST fusion protein per $\mathrm{ml}$ of wet beads. A GST fusion protein with mouse ICAD was produced by a similar method ${ }^{25}$.

Purification of ICAD and CAD. All packed columns used for protein purification were from Pharmacia. To purify ICAD, mouse WR19L cells were suspended $\left(2 \times 10^{9}\right.$ cells per $\left.\mathrm{ml}\right)$ in buffer B (10 mM HEPES-KOH, pH 7.0, $50 \mathrm{mM} \mathrm{NaCl}, 5 \mathrm{mM} \mathrm{MgCl} 2,5 \mathrm{mM}$ EGTA, $10 \%$ glycerol, and $1 \mathrm{mM} \mathrm{DTT}$ ) supplemented with a mixture of protease inhibitors ( $1 \mathrm{mM} \mathrm{APMSF}, 1 \mu \mathrm{g} \mathrm{ml}^{-1}$ aprotinin, $1 \mu \mathrm{g} \mathrm{ml}^{-1}$ leupeptin, and $1 \mu \mathrm{g} \mathrm{ml}^{-1}$ pepstatin A). Cells were disrupted by three cycles of freezing and thawing in a Dounce homogenizer, accompanied by grinding with a pestle during each thawing cycle. The homogenate was spun at $30,000 \mathrm{~g}$ for $30 \mathrm{~min}$ and at $100,000 \mathrm{~g}$ for $12 \mathrm{~h}$. The S-100 fraction $(1,710 \mathrm{mg})$ was applied to a DEAE-Sepharose FF column ( $170 \mathrm{ml}$ bed volume). The column was washed with buffer $\mathrm{B}$, and eluted with a $50-350 \mathrm{mM}$ linear $\mathrm{NaCl}$ gradient. Active fractions were pooled, fractionated with ammonium sulphate at 25 to $50 \%$ saturation, and dissolved in buffer C (buffer B without $50 \mathrm{mM}$ $\mathrm{NaCl}$ ) containing $1 \mathrm{M}$ ammonium sulphate. The sample was applied to a butyl-sepharose-4 FF column ( $18 \mathrm{ml}$ bed volume) equilibrated with buffer $\mathrm{C}$ containing $1 \mathrm{M}$ ammonium sulphate. The column was eluted with an ammonium sulphate linear descending gradient of 1.0 to $0 \mathrm{M}$. Active fractions were pooled, and ammonium sulphate was added to $0.8 \mathrm{M}$. After removing insoluble material, the sample was applied to a phenyl-superose HR5/5 column and eluted with buffer C. Active fractions were pooled, and Tween 20 was added to $0.02 \%$. The sample was loaded onto a Superdex-200 HR10/30 gel filtration column equilibrated with buffer D (buffer B containing $0.02 \%$ Tween 20 ). Each active fraction was heated at $90^{\circ} \mathrm{C}$ for $15 \mathrm{~min}$, and the precipitates were removed by centrifugation at $100,000 \mathrm{~g}$ for $30 \mathrm{~min}$.

To purify CAD, lymph nodes $(\sim 70.4 \mathrm{~g}$ ) were prepared from MRL-lpr mice (4-6 months old; from SLC), and suspended in $244 \mathrm{ml}$ of extraction buffer (12.5 mM PIPES-NaOH, 7.5 mM HEPES-KOH, pH 7.0, $12.5 \mathrm{mM} \mathrm{KCl,}$ $37.5 \mathrm{mM} \mathrm{NaCl}, 2 \mathrm{mM} \mathrm{MgCl}$, $5 \mathrm{mM}$ EGTA, $1 \mathrm{mM}$ DTT, $5 \mathrm{mM}$ cytochalasin B, $1 \mathrm{mM}$ PMSF, $1 \mu \mathrm{g} \mathrm{ml}^{-1}$ leupeptin, $1 \mu \mathrm{g} \mathrm{ml}^{-1}$ pepstatin $\mathrm{A}$, and $30 \mathrm{mM} \beta$ glycerophosphate). Cells were disrupted by three cycles of freezing and thawing, and spun at $100,000 \mathrm{~g}$ for $2 \mathrm{~h}$. The S-100 fraction was incubated at $4{ }^{\circ} \mathrm{C}$ for $30 \mathrm{~min}$ with $0.1 \mathrm{mM}$ of bio-DEVD-cmk (Peptide Institute) to inactivate caspase 3. The sample was fractionated with ammonium sulphate at 25 to $50 \%$ saturation, dialysed against buffer E (10 mM Tris- $\mathrm{HCl}, \mathrm{pH} 8.9,50 \mathrm{mM} \mathrm{NaCl}$, $20 \%$ (v/v) glycerol, $1 \mathrm{mM}$ DTT, $0.1 \mathrm{mM}$ APMSF, 0.15\% CHAPS), and applied to a $20 \mathrm{ml}$ HiTrap heparin column. After washing with buffer E containing $150 \mathrm{mM} \mathrm{NaCl}$, proteins were eluted with buffer E containing $500 \mathrm{mM} \mathrm{NaCl}$, and passed through a PD-10 column equilibrated with buffer E. The sample was loaded onto a $6 \mathrm{ml}$ resource-Q column equilibrated with buffer $\mathrm{E}$, and the retained proteins were eluted with a linear 150 to $400 \mathrm{mM} \mathrm{NaCl}$ gradient. Active fractions were pooled and passed through a PD-10 column equilibrated with buffer F (20 mM HEPES-KOH, pH 7.0, 20\% (v/v) glycerol, $0.1 \mathrm{mM}$ APMSF, $1 \mathrm{mM}$ DTT and $0.15 \%$ CHAPS). The sample was loaded onto a $1 \mathrm{ml}$ resource-S column and the retained proteins were eluted with a $15-\mathrm{ml}$ linear $\mathrm{NaCl}$ gradient from 0 to $500 \mathrm{mM}$. Active fractions were pooled and passed through a PD-10 column equilibrated with buffer $\mathrm{G}$ (10 mM HEPES-KOH, pH 7.0, $50 \mathrm{mM}$ $\mathrm{NaCl}, 20 \%$ (v/v) glycerol, $40 \mathrm{mM} \beta$-glycerophosphate, $2 \mathrm{mM}$ EGTA, $0.1 \mathrm{mM}$ APMSF, $1 \mathrm{mM}$ DTT, $0.02 \%$ Tween 20 ). The sample was incubated at $4{ }^{\circ} \mathrm{C}$ overnight with $2.6 \mu \mathrm{g}$ caspase 3 , then caspase 3 was inactivated by incubating at $4{ }^{\circ} \mathrm{C}$ for $30 \mathrm{~min}$ with $5 \mu \mathrm{M}$ bio-DEVD-cmk. GST-DFF45 affinity beads $(25 \mu \mathrm{l}$ bed volume) were added to the mixture, which was rocked at $4^{\circ} \mathrm{C}$ for $2 \mathrm{~h}$. After washing with buffer $\mathrm{G}$, beads were suspended in $50 \mu$ l buffer $\mathrm{G}$. Caspase 3 $(2 \mu \mathrm{g})$ and thrombin $(6 \mu \mathrm{g})$ were added to the suspension and incubated at room temperature overnight and at $37^{\circ} \mathrm{C}$ for $1 \mathrm{~h}$. Beads were removed by centrifugation; proteins released from the beads were collected.

Peptide sequence analysis. The sample was electrophoresed on a $10-20 \%$ gradient polyacrylamide gel and blotted onto a polyvinylidine difluoride membrane (Problot, Applied Biosystems). After staining with ponceau $S$, the immobilized protein ( $\sim 10 \mathrm{pmol}$ for ICAD, $2-4$ pmol for CAD) was reduced, $S$ carboxymethylated, and digested in situ with Acromobacter protease I (ICAD) ${ }^{41}$ or with Acromobacter protease I and Asp-N (for CAD) ${ }^{42}$. Peptides released from the membrane were fractionated by reverse-phase high-performance liquid chromatography with a Wakosil-II AR C18 300A column (Wako Pure Chemical), and sequenced using a protein sequencer (model PPSQ-23, Shimadzu). Cloning of mouse CAD and ICAD cDNAs. A cDNA library of mouse WR19L cells was constructed (M. Tanaka and S.N., unpublished results). To isolate mouse ICAD cDNA, two oligonucleotides (5'-GATTCCGATGGAGGGAC-3' and 5'-GATAAACTCAGCTCTGG-3') were designed from EST clone 615712, which encodes one of the peptide sequences of purified ICAD (Fig. 3). A cDNA (476 bp) was amplified by PCR from a WR19L cDNA library, labelled with ${ }^{32} \mathrm{P}$ and used as a probe to screen the WR19L cDNA library. Screening of $2 \times 10^{5}$ clones by colony hybridization yielded 8 positive clones. Of these, 2 clones carried ICAD-L and 2 clones carried ICAD-S cDNA. Mouse CAD cDNA was cloned from the cDNA library by PCR using the following degenerate primers, whose design was based on the amino-acid sequence of purified mouse CAD: the sense primer was $5^{\prime}-\mathrm{AA}(\mathrm{A} / \mathrm{G}) \mathrm{TT}(\mathrm{C} / \mathrm{T}) \mathrm{GGIGTIGCIGC-3}$; the antisense primer was $5^{\prime}$-TGI(C/G)(A/T)IAC(A/G)TG(A/G)TGIA(A/G)IA(A/ $\mathrm{G})(\mathrm{A} / \mathrm{G}) \mathrm{TC}-3^{\prime}$ (I, inosine). A PCR product (332 bp) was used as a probe to 
screen the WR19L cDNA library by colony hybridization. Eight positive clones were obtained out of $1 \times 10^{6}$ clones. Of these, 4 clones carried the full-length coding sequence of mouse CAD. DNA sequencing was done on AlfFred (Pharmacia) or PRIZM 310 (Applied Biosystems) sequencers.

Transfection of COS cells, and in vitro transcription and translation. Plasmid pEF-ICAD-L is a mammalian expression vector of mouse ICAD-L, described in the accompanying Letter ${ }^{25}$. Monkey COS7 cells were transfected with plasmid DNA by electroporation as described ${ }^{43}$. After culturing at $37^{\circ} \mathrm{C}$ for $48 \mathrm{~h}$, cells were suspended in $0.1 \mathrm{ml}$ buffer $\mathrm{G}$, disrupted by repeated freezing and thawing, and spun to remove cell debris and nuclei. To express CAD in a cell-free system, mouse CAD cDNA was placed under the T7 promoter of the pcDNAI/Amp vector (Invitrogen), and designated pcDNA-CAD. Coupled transcription and translation of CAD was carried out using a TNT in vitro transcription/translation kit (Promega) according to the manufacturer's instructions. pcDNA-CAD DNA $(1 \mu \mathrm{g})$ was incubated at $30^{\circ} \mathrm{C}$ for $2 \mathrm{~h}$ with $40 \mu \mathrm{l} \mathrm{TNT}$ reagents and $40 \mu \mathrm{Ci}{ }^{35} \mathrm{~S}$-methionine (Amersham) in the presence of $160 \mathrm{ng}$ GST-ICAD-L fusion protein. To immunoprecipitate the ICAD-L/CAD complex, the reaction mixture was diluted to $0.5 \mathrm{ml}$ with buffer $\mathrm{G}$, and $10 \mu \mathrm{l}$ of anti-flag M2 affinity beads (Kodak; $3 \mathrm{mg}$ IgG per $\mathrm{ml}$ of beads) was added. After incubation at $4{ }^{\circ} \mathrm{C}$ for $2 \mathrm{~h}$, beads were recovered by centrifugation and suspended in buffer $\mathrm{G}$.

Received 19 November; accepted 1 December 1997.

1. Jacobson, M. D., Weil, M. \& Raff, M. C. Programmed cell death in animal development. Cell 88, 347 354 (1997).

2. Nagata, S. Apoptosis by death factor. Cell 88, 355-365 (1997).

3. Wyllie, A. H., Kerr, J. F. R. \& Currie, A. R. Cell death: the significance of apoptosis. Int. Rev. Cytol. 68 , 251-306 (1980).

4. Compton, M. M. A biochemical hallmark of apoptosis: internucleosomal degradation of the genome. Cancer Metast. Rev. 11, 105-119 (1992).

5. Wyllie, A. H., Morris, R. G., Smith, A. L. \& Dunlop, D. Chromatin cleavage in apoptosis: association with condensed chromatin morphology and dependence on macromolecular synthesis. J. Pathol. 142, 66-77 (1984)

6. Wyllie, A. H. Glucocorticoid-induced thymocyte apoptosis is associated with endogenous endonuclease activation. Nature 284, 555-556 (1980).

7. Peitsch, M. C. et al. Characterization of the endogenous deoxyribonuclease involved in nuclear DNA degradation during apoptosis (programmed cell death). EMBO J. 12, 371-377 (1993).

8. Montague, J. W., Hughes, F. J. \& Cidlowski, J. A. Native recombinant cyclophilins A, B, and C degrade DNA independently of peptidylpropyl cis-trans-isomerase activity. Potential roles of cyclophilins in apoptosis. J. Biol. Chem. 272, 6677-66784 (1997).

9. Barry, M. \& Eastman, A. Identification of deoxyribonuclease II as an endonuclease involved in apoptosis. Arch. Biochem. Biophys. 300, 440-450 (1993).

10. Nagata, S. \& Golstein, P. The Fas death factor. Science 267, 1449-1456 (1995).

11. Itoh, N. et al. The polypeptide encoded by the cDNA for human cell surface antigen Fas can mediate apoptosis. Cell 66, 233-243 (1991)

12. Schulze-Osthoff, K., Walczak, H., Dröge, W. \& Krammer, P. H. Cell nucleus and DNA fragmentation are not required for apoptosis. J. Cell. Biol. 127, 15-20 (1994).

13. Enari, M., Hug, H. \& Nagata, S. Involvement of an ICE-like protease in Fas-mediated apoptosis. Nature 375, 78-81 (1995).

14. Enari, M., Talanian, R. V., Wong, W. W. \& Nagata, S. Sequential activation of ICE-like and CPP32-like proteases during Fas-mediated apoptosis. Nature 380, 723-726 (1996).

15. Longthorne, V. \& Williams, G. Caspase activity is required for commitment to Fas-mediated apoptosis. EMBO J. 16, 3805-3812 (1997)

16. Armstrong, R. C. et al. Fas-induced activation of the cell death-related protease CPP32 is inhibited by Bcl-2 and by ICE family protease inhibitors. J. Biol. Chem. 271, 16850-16855 (1996).
17. Muzio, M. et al. FLICE, a novel FADD-homologous ICE/CED-3-like protease, is recruited to the CD95 (Fas/APO-1) death-inducing signaling complex. Cell 85, 817-827 (1996).

18. Boldin, M. P., Goncharov, T. M., Goltsev, Y. V. \& Wallach, D. Involvement of MACH, a novel MORT1/ FADD-interacting protease, in Fas/APO-1- and TNF receptor-induced cell death. Cell 85, 803-815 (1996).

19. Henkart, P. A. ICE family protease: mediators of all apoptotic cell death? Immunity 4, 195-201 (1996).

20. Fraser, A. \& Evan, G. A license to kill. Cell 85, 781-784 (1996).

21. Martin, S. \& Green, D. Protease activation during apoptosis: death by a thousand cuts. Cell 82, 349352 (1995).

22. Enari, M., Hase, A. \& Nagata, S. Apoptosis by a cytosolic extract from Fas-activated cells. EMBO J. 14, 5201-5208 (1995).

23. Martin, S. J. et al. Cell-free reconstitution of Fas-, UV radiation- and ceramide-induced apoptosis. EMBO J. 14, 5191-5200 (1995)

24. Liu, X., Zou, H., Slaughter, C. \& Wang, X. DFF, a heterodimeric protein that functions downstream of caspase-3 to trigger DNA fragmentation during apoptosis. Cell 89, 175-184 (1997).

25. Sakahira, H., Enari, M. \& Nagata, S. Cleavage of CAD inhibitor in CAD activation and DNA degradation during apoptosis. Nature 391, 96-99 (1998).

26. Blanar, M. A. \& Rutter, W. J. Interaction cloning: identification of a helix-loop-helix zipper protein that interacts with c-Fos. Science 256, 1014-1018 (1992).

27. Zakut, R. et al. Nucleotide sequence of the rat skeletal muscle actin gene. Nature 298, 857-859 (1982).

28. Dingwall, C. \& Laskey, R. Nuclear targeting sequences-a consensus? Trends Biol. Sci. 16, 478-481 (1991).

29. Cohen, J. J., Duke, R. C., Fadok, V. A. \& Sellins, K. S. Apoptosis and programmed cell death in immunity. Annu. Rev. Immunol. 10, 267-293 (1992).

30. Shiokawa, D., Iwamatsu, A. \& Tamura, S. Purification, characterization, and amino acid sequencing of DNase $\gamma$ from rat spleen. Arch. Biochem. Biophys. 346, 15-20 (1997).

31. Batistatou, A. \& Green, L. Internucleosomal DNA cleavage and neuronal cell survival/death. J. Cell Biol. 122, 523-532 (1993).

32. Mogil, R. et al. Role of DNA fragmentation in T cell activation-induced apoptosis in vitro and in vivo. J. Immunol. 152, 1674-1683 (1994).

33. Verma, I., Stevenson, J., Schwarz, E., Van Antwerp, D. \& Miyamoto, S. ReI/NF-кB/IкB family: intimate tales of association and dissociation. Genes Dev. 9, 2723-2735 (1995).

34. Baldwin, A. The NF-кB and IкB proteins: new discoveries and insights. Annu. Rev. Immunol. 14, 649681 (1996).

35. Beg, A. et al. IкB interacts with the nuclear localization sequences of the subunits of NF-кB: a mechanism for cytoplasmic retention. Genes Dev. 6, 1899-1913 (1992).

36. Wallis, R. et al. In vivo and in vitro characterization of overproduced colicin E9 immunity protein. Eur. J. Biochem. 207, 687-695 (1992).

37. Hartl, F.-U., Hlodan, R. \& Langer, T. Molecular chaperones in protein folding: the art of avoiding sticky situations. Trends Biol. Sci. 19, 20-25 (1994).

38. Shi, G. et al. $\beta$-Subunits promote $\mathrm{K}^{+}$channel surface expression through effects early in biosynthesis. Neuron 16, 843-852 (1996)

39. Chen, P. \& Hochstrasser, M. Autocatalytic subunit processing couples active site formation in the $20 \mathrm{~S}$ proteasome to completion of assembly. Cell 86, 961-972 (1996).

40. Ogasawara, J. et al. Lethal effect of the anti-Fas antibody in mice. Nature 364, 806-809 (1993).

41. Iwamatsu, A. S-carboxymethylation of proteins transferred onto polyvinylidine difluoride membranes followed by in situ protease digestion and amino acid microsequencing. Electrophoresis 13, 142-147 (1992).

42. Iwamatsu, A. \& Yoshida-Kubomura, N. Systematic peptide fragmentation of polyvinylidine difluoride (PVDF)-immobilized proteins prior to microsequencing. J. Biochem. (Tokyo) 120, 29-34 (1996).

43. Suda, T., Takahashi, T., Golstein, P. \& Nagata, S. Molecular cloning and expression of the Fas ligand: a novel member of the tumor necrosis factor family. Cell 75, 1169-1178 (1993).

44. Hager, D. A. \& Burgess, R. R. Elution of proteins from sodium dodecyl sulfate-polyacrylamide gels, removal of sodium dodecyl sulfate, and renaturation of enzymatic activity: results with sigma subunit of Escherichai coli RNA polymerase, wheat germ DNA topoisomerase, and other enzymes. Analyt. Biochem. 109, 76-86 (1980).

Acknowledgements. We thank R. V. Talanian for the caspase 3 expression system, M. A. Blanar for pGEX$2 \mathrm{~T}[128 / 129]$, and S. Kumagai for secretarial assistance. This work was supported in part by Grants-in-Aid from the Ministry of Education, Science, Sports and Culture in Japan.

Correspondence and requests for materials should be addressed to S.N. (e-mail: nagata@genetic.med. osaka-u.ac.jp). The nucleotide sequence data will appear in the DDBJ, EMBL and Genbank nucleotide sequence databases under the accession number AB009375, AB009376 and AB009377 for mouse ICAD-L, ICAD-S and CAD, respectively. 
the order parameter may allow locally stable phase differences of $\pi$ to exist across a weak link between two containers of superfluid ${ }^{3} \mathrm{He}$. The depth of the observed energy well at $\Delta \phi=\pi$ indicates the existence of a strong term in the $I(\Delta \phi)$ function which is proportional to $\sin (2 \Delta \phi)$. The microscopic reason for the existence of this term is so far unknown, and potential explanations in terms of local textures near the apertures, trapped circulation, and internal degrees of freedom of the superfluid will provide fruitful ground for further research.

Note added in proof: It has recently been pointed out ${ }^{19}$ that there is a theoretical prediction of a second branch of $I(\Delta \phi)$ at $\Delta \phi=\pi$ in superfluid ${ }^{3} \mathrm{He}$, when the $n$-vector fields are antiparallel on opposite sides of the weak link.

Received 20 November 1997; accepted 16 February 1998.

1. Bulaevskii, L. N., Kuzii, V. V. \& Sobyanin, A. A. Superconducting system with weak coupling to the current in the ground state. JETP Lett. 25, 290-293 (1977)

2. Geshkenbein, V. B., Larkin, A. I. \& Barone, A. Vortices with half magnetic flux quanta in "heavy fermion" superconductors. Phys. Rev. B 36, 235-238 (1987).

. Wollman, D. A., Van Harlingen, D. J., Lee, W. C., Ginsberg, D. M. \& Legett, A. J. Experimental determination of the superconducting pairing state in $\mathrm{YBCO}$ from the phase coherence of $\mathrm{YBCO}-\mathrm{Pb}$ dc SQUIDs. Phys. Rev. Lett. 74, 797-801 (1993).

4. Brawner, D. A. \& Ott, H. R. Evidence for an unconventional superconducting order parameter in $\mathrm{YBa}_{2} \mathrm{Cu}_{3} \mathrm{O}_{6.9}$. Phys. Rev. B 50, 6530-6533 (1994).

Mathai, A., Gim, Y., Black, R. C., Amar, A. \& Wellstood, F. C. Experimental proof of a time-reversalinvariant order parameter with a $\pi$ phase shift in $\mathrm{YBa}_{2} \mathrm{Cu}_{3} \mathrm{O}_{7-8}$. Phys. Rev. Lett. 74, 4523-4527 (1995).

6. Tsuei, C. C. et al. Pairing symmetry and flux quantization in a tricrystal superconducting ring of $\mathrm{YBa}_{2} \mathrm{Cu}_{3} \mathrm{O}_{7-\delta}$. Phys. Rev. Lett. 73, 593-597 (1994).

Tsuei, C. C. et al. Symmetry of the order parameter of the high- $\mathrm{T}_{\mathrm{c}}$ superconductor $\mathrm{YBa}_{2} \mathrm{Cu}_{3} \mathrm{O}_{7-\delta}$ Nature 373, 225-229 (1995).

8. Tsuei, C. C. et al. Pairing symmetry in single layer tetragonal $\mathrm{Tl}_{2} \mathrm{Ba}_{2} \mathrm{CuO}_{6+\delta}$ superconductors. Science 271, 329-332 (1996).

9. Smerzi, A., Fantoni, S., Giovanazzi, S. \& Shenoy, S. R. Quantum coherent atomic tunneling between two trapped Bose-Einstein condensates. Phys. Rev. Lett. 79, 4950-4953 (1997).

10. Pereverzev, S. V., Backhaus, S., Loshak, A., Davis, J. C. \& Packard, R. E. Quantum oscillations between two weakly coupled reservoirs of superfluid ${ }^{3}$ He. Nature 388, 449-451 (1997).

11. Paik, H. J. Superconducting tunable-diaphragm transducer for sensitive acceleration measurements J. Appl. Phys. 47, 1168-1178 (1976).

12. Tilley, D. R. \& Tilley, J. Superfluidity and Superconductivity (Hilger, New York, 1990).

13. Monien, H. \& Tewordt, L. Theory of Josephson flow oscillations in superfluid ${ }^{3} \mathrm{He}-\mathrm{B}$. J. Low Temp. Phys. 62, 277-300 (1986)

14. Backhaus, S., Pereverzev, S. V., Loshak, A., Davis, J. C. \& Packard, R. E. Direct measurement of the current-phase relation of a superfluid He-3-B weak link. Science 278, 1435-1438 (1997).

15. Barone, A. \& Paterno, G. Physics and Applications of the Josephson Effect Section 1.6 (Wiley, New York, 1982)

16. Van Harlingen, D. J. Phase-sensitive tests of the symmetry of the pairing states in the high-temperature superconductors-Evidence for $\mathrm{d}_{x^{2}}-y^{2}$ symmetry. Rev. Mod. Phys. 67, 515-535 (1997).

17. Kouznetsov, K. A. et al. $c$-axis Josephson tunneling between $\mathrm{YBa}_{2} \mathrm{Cu}_{3} \mathrm{O}_{7-\delta}$ and $\mathrm{Pb}$ : direct evidence for mixed order parameter symmetry in high-Tc superconductors. Phys. Rev. Lett. 79, 3050-3053 (1997).

18. Vollhardt, D. \& Wolfle, P. The Superfluid Phases of Helium-3 Section 7-2 (Taylor \& Francis, New York, 1990).

19. Thuneberg, E. V. Two-dimensional Ginzburg-Landau simulation of the Josephson effect in superfluid ${ }^{3}$ He. Europhys. Lett. 7, 441-446 (1998).

Acknowledgements. We thank D. Rokhsar, D.-H. Lee, S. Vitale, D. Weiss, S. Bahcall, R. Chiao, A. Smerzi and D. J. Van Harlingen for conversations. This work was supported in part by the National Science Foundation, the Office of Naval Research, the Packard Foundation, and the A.P. Sloan Foundation.

Phase-mapping of periodically domain-inverted $\mathrm{LiNbO}_{3}$ with coherent $X$-rays

Z. H. Hu*, P. A. Thomas ${ }^{\star}$, A. Snigirev $\dagger$, I. Snigireva $\dagger$, A Souvorov $\dagger$, P. G. R. Smith $\ddagger$, G. W. Ross $\ddagger$ \& S. Teat $₫$

* Department of Physics, University of Warwick, Coventry CV4 7AL, UK $\dagger$ ESRF, BP 220, F-38043 Grenoble, France

$\ddagger$ Optoelectronics Research Centre, University of Southampton,

Southampton SO17 1BJ, UK

$\$$ Daresbury Laboratory, Warrington WA4 4AD, UK

A varying refractive index across a wavefront leads to a change in the direction of propagation of the wave $e^{1,2}$. This provides the basis for phase-contrast imaging of transparent or weakly absorbing materials with highly coherent $\mathrm{X}$-ray beams ${ }^{3,4}$. Lattice distortions can also change the direction of propagation of a wave field diffracted from a crystal. Here we report the use of this principle to effect phase-contrast imaging of the domain structure of a ferroelectric material, lithium niobate. A periodically domaininverted structure for quasi-phase-matching of second-harmonic generation is created in this material, in which the direction of spontaneous polarization is sequentially inverted. Because of complex interactions during domain-inversion processing, this is accompanied by lattice distortions across the domain walls. These distortions split the diffracted wavefront of a beam of coherent X-rays from an advanced synchrotron source, giving rise to a pattern of interference that reflects the underlying pattern of lattice distortions. These results show that this phasecontrast imaging technique with sub-micrometre spatial resolution permits the non-destructive, highly sensitive phase-mapping of various structural defects and distortions introduced into materials during processing.

Interference and phase-contrast imaging at optical wavelengths can be conveniently realized by using optical lenses ${ }^{1}$. But this is not the case for hard X-ray wavelengths because the refractive index for $\mathrm{X}$-rays differs from unity by only $10^{-5}$ to $10^{-6}$. Therefore, methods which are free of lenses have been used for X-ray phase-contrast imaging such as the Bonse-Hart interferometer ${ }^{5}$ that splits and subsequently recombines coherently-related X-ray beams to generate interference patterns. However, the stringent experimental conditions required with a conventional X-ray source have limited the applications of the phase-contrast imaging technique in research in condensed-matter physics, materials and biological sciences. This technique has recently aroused much interest because the high degree of coherence of intense X-ray beams provided by the European Synchrotron Radiation Facility (Grenoble) has made phase-contrast imaging possible in a convenient manner ${ }^{4,6,7}$.

We have explored the possibility of phase-contrast imaging of periodic domain inversion in ferroelectric nonlinear optical materials. Periodic domain inversion refers to the deliberate introduction of a periodic array of domains of alternating structural polarity into a polar crystal, displacing the cations and anions of the structure by applying an external electric field such that the resulting spontaneous polarization is reversed with respect to the original. This generates a spatially periodic modulation of the nonlinear coefficient along the direction of wave propagation that enables quasi-phase-matching of any frequency-doubling interaction within the transparency range of the crystal according to the choice of the period of modulation ${ }^{8}$. Lattice distortions occur during domain-inversion processing because of complex interactions between the physical effects taking place, for example, the converse piezoelectric and/or pyroelectric effects, and the dynamic process of domain inversion ${ }^{9-11}$.

The crystal used for our studies is $\mathrm{LiNbO}_{3}$. A domain-inverted structure of period $30 \mu \mathrm{m}$ was fabricated in a $\mathrm{LiNbO}_{3}$ sample with a thickness of $200 \mu \mathrm{m}$ via electric-field poling. A synchrotron-radiation X-ray experiment was performed at the ESRF optics beamline (BL10/D5) which is on a bending magnet. The experimental configuration is schematically shown in Fig. 1.

Sets of synchrotron X-ray images of the 006 symmetric reflection are shown in Fig. 2a-e. Periodic-contrast lines appear with alternating spacings of 22 and $8 \mu \mathrm{m}$ in Fig. $2 \mathrm{a}$ which was taken with a film positioned $\sim 5 \mathrm{~mm}$ away from the sample. They are images of the periodic inversion-domain walls. The vertical black-white lines or dots are images of segments or outcrops of dislocations. As the film-to-sample distance increases, the intensity variations become stronger, as shown in Fig. 2b-e. Furthermore, extra fringes appear in the domain-inverted regions of Fig. 2b-e compared with those of Fig. 2a. Clearly, the intensity variations observed above cannot be explained simply by a diffraction imaging or topographic effect. Instead, they mainly arise from interference, that is, the fringe patterns observed in Fig. 2b-e arise from phase contrast. As shown in Fig. $2 \mathrm{a}$ and $\mathrm{e}$, the interference fringes run parallel to the domain 
walls, but appear in the domain-inverted regions only. No interference fringes have been observed outside the treated regions except in the areas close to the border between the treated and untreated blocks. This indicates that the interference fringes are directly related to the presence of domain-inversion.

Figure $3 \mathrm{a}, \mathrm{b}$ show the rocking curves of the 006 and 0012 reflections obtained using a Philips high-resolution Materials Research Diffractometer ${ }^{12}$ in Warwick University. The measurements clearly indicate that the 006 rocking curve has been broadened significantly by domain-inversion processing, whereas the fullwidth at half-maximum (FWHM) of the 0012 reflection has not been much changed. Furthermore, the experimental FWHM of the 0012 reflection is much narrower than that of the 006 reflection in the domain-inverted regions. This is contrary to the result obtained in the untreated region where the experimental FWHM of the 0012 reflection is 1.7 times that of 006 because of the strong broadening effect of the instrument function on the high Bragg-angle reflection ${ }^{10}$. A further measurement via mapping is shown in

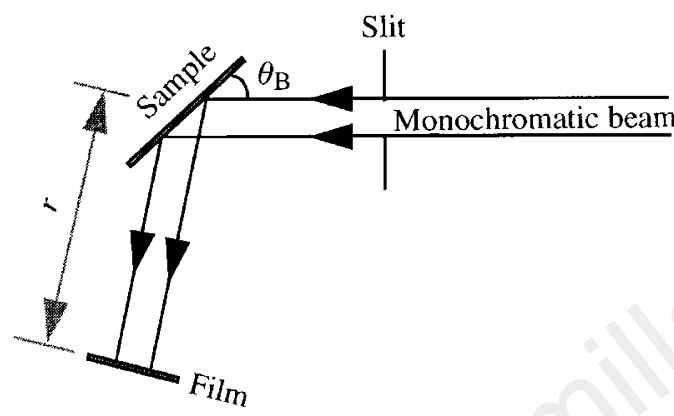

Fig. $3 \mathrm{c}$ and $\mathrm{d}$, which shows two peaks overlapped along the $\omega$ scan direction in the 006 diffraction map in contrast to one single peak in the 0012 diffraction map. We note that the 006 symmetric reflection is much more sensitive to surface strains than the 0012 reflection because of the diffraction geometry and lower penetration depth for the former reflection ${ }^{10}$. Then, it is clear that the abnormal broadening of the 006 rocking curve results from the component of lattice tilts $\delta \omega$ with respect to the goniometer axis in the top few micrometres of the surface between the inverted domains and original lattices.

It is the lattice tilting that is responsible for the spatial splitting and recombination of the coherently-related beams diffracted from the different parts for yielding phase contrast. This is analogous to the case of 'division of wavefront' (ref. 1) in optics where a monochromatic beam is divided by passage through a system such as apertures placed side by side. In our synchrotron experiment, the incident beam approximates to a linearly polarized monochromatic plane wave, and the $\mathrm{LiNbO}_{3}$ sample should be

Figure 1 Schematic drawing of the experimental configuration for taking $X$-ray phase-contrast images. A wavelength of $0.1 \mathrm{~nm}$ is selected by a perfect doublecrystal $\mathrm{Si}$ (111) monochromator. The sample is set such that the domain walls are parallel to the plane of incidence of the X-ray beam. The vertical divergence of the incident synchrotron beam determined by the intrinsic width of the Si (111) reflection is $\sim 2 \times 10^{-5} \mathrm{rad}$. The wavelength dispersion, $\Delta \lambda / \lambda$, of the output beam from the monochromator was $\sim 10^{-4}$, where $\lambda$ is the $X$-ray wavelength and $\Delta \lambda$ is the distribution of wavelengths. This resulted in a longitudinal coherence length, $\delta^{2} / 2 \Delta \lambda$, of about $0.5 \mu \mathrm{m}$. The sample-to-source distance, $R$, was $40 \mathrm{~m}$, the source size, $d$, was $\sim 100 \mu \mathrm{m}$, the transverse coherence length, $\lambda R / 2 d$, was thus $\sim 20 \mu \mathrm{m}$ for the wavelength of $0.1 \mathrm{~nm}$. Kodak high-resolution films were used to record the X-ray images.
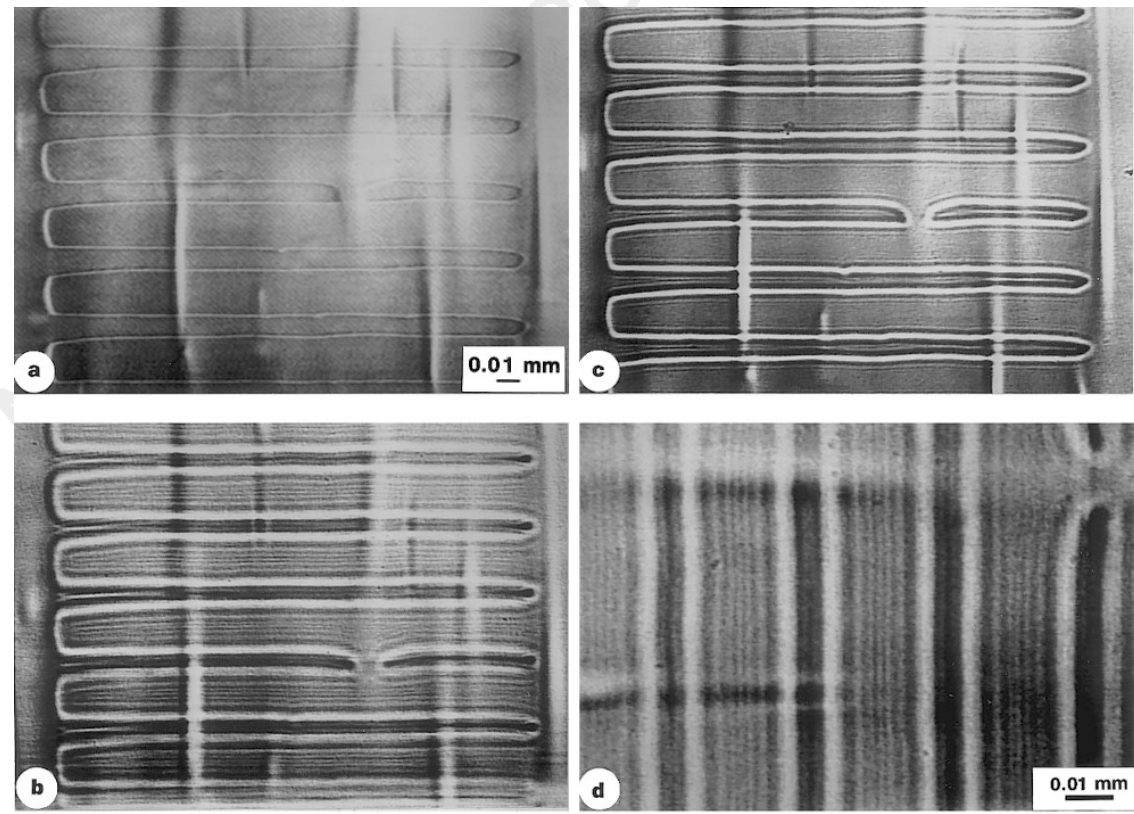

Figure 2 High-resolution phase-contrast images of a periodically domain-inverted $\mathrm{LiNbO}_{3}$ crystal taken using the symmetric Bragg 006 reflection, $2 \theta_{\mathrm{B}}=25^{\circ}$. The filmto-sample distances are $0.005 \mathrm{~m}(\mathbf{a}), 0.1 \mathrm{~m}(\mathbf{b}), 0.2 \mathrm{~m}(\mathbf{c})$, $0.2 \mathrm{~m}(\mathbf{d})$ and $0.5 \mathrm{~m}(\mathbf{e})$. The periodic black-white contrast with a periodicity of $30 \mu \mathrm{m}$ shown in a corresponds to the inversion-domain walls. The image in $\mathbf{a}$ is mainly of a conventional X-ray topographic nature, whereas intensity variations produced by interference are dominant in b-e where the interference occurs in periodically domain-inverted regions. Magnification in $\mathbf{a}, \mathbf{b}, \mathbf{c}$ and $\mathbf{e}$ is the same; $\mathbf{d}$ is an enlargement of a region in $\mathbf{c}$, rotated anticlockwise by $90^{\circ}$.

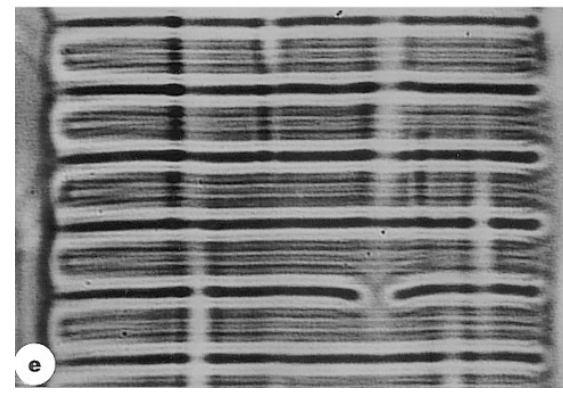


treated as semi-infinitely thick considering the short extinction distance of $4.4 \mu \mathrm{m}$ for reflection 006 with wavelength $0.1 \mathrm{~nm}$. Therefore, there would be only one tie point or wave point (say, $\mathrm{T}_{2}$ ) excited on the dispersion surface ${ }^{13-15}$ (Fig. 4a) and no interference would happen, unlike the Laue case if the sample was a perfect single crystal. However, because of the tilts of the lattice planes, the coherently-related beams diffracted essentially from two different misorientated parts are split inside the crystal, then recombined outside the crystal, which gives rise to interference. That is, a pair of tie points belonging to the same branch of the dispersion surface (say, $\mathrm{T}_{2}$ and $\mathrm{T}_{2^{\prime}}$ ) are excited (Fig. $4 \mathrm{~b}$ ); these two tie points are directly related to the two misorientated parts tilted by an angle of $\Delta \omega$ about the horizontal axis (although we discuss here the case of two split diffracted beams, this does not lead to a loss of generality). As the tie points $\mathrm{T}_{2}$ and $\mathrm{T}_{2^{\prime}}$ are excited, the amplitudes at the sample surface, $Z=0$, are given by

$$
\begin{aligned}
& \mathbf{D}_{\mathrm{o}}^{\mathrm{i}}=\mathbf{D}_{\mathrm{o}_{2}}+\mathbf{D}_{\mathrm{o}_{2^{\prime}}} \\
& \mathbf{D}_{\mathrm{g}}^{\mathrm{e}}=\mathbf{D}_{\mathrm{g}_{2}}+\mathbf{D}_{\mathrm{g}_{2^{\prime}}}
\end{aligned}
$$

where $\mathbf{D}_{\mathrm{o}}^{\mathrm{i}}$ and $\mathbf{D}_{\mathrm{g}}^{\mathrm{e}}$ are the vector amplitudes of the outside incident and diffracted waves, respectively, and the subscripts 2 and $2^{\prime}$
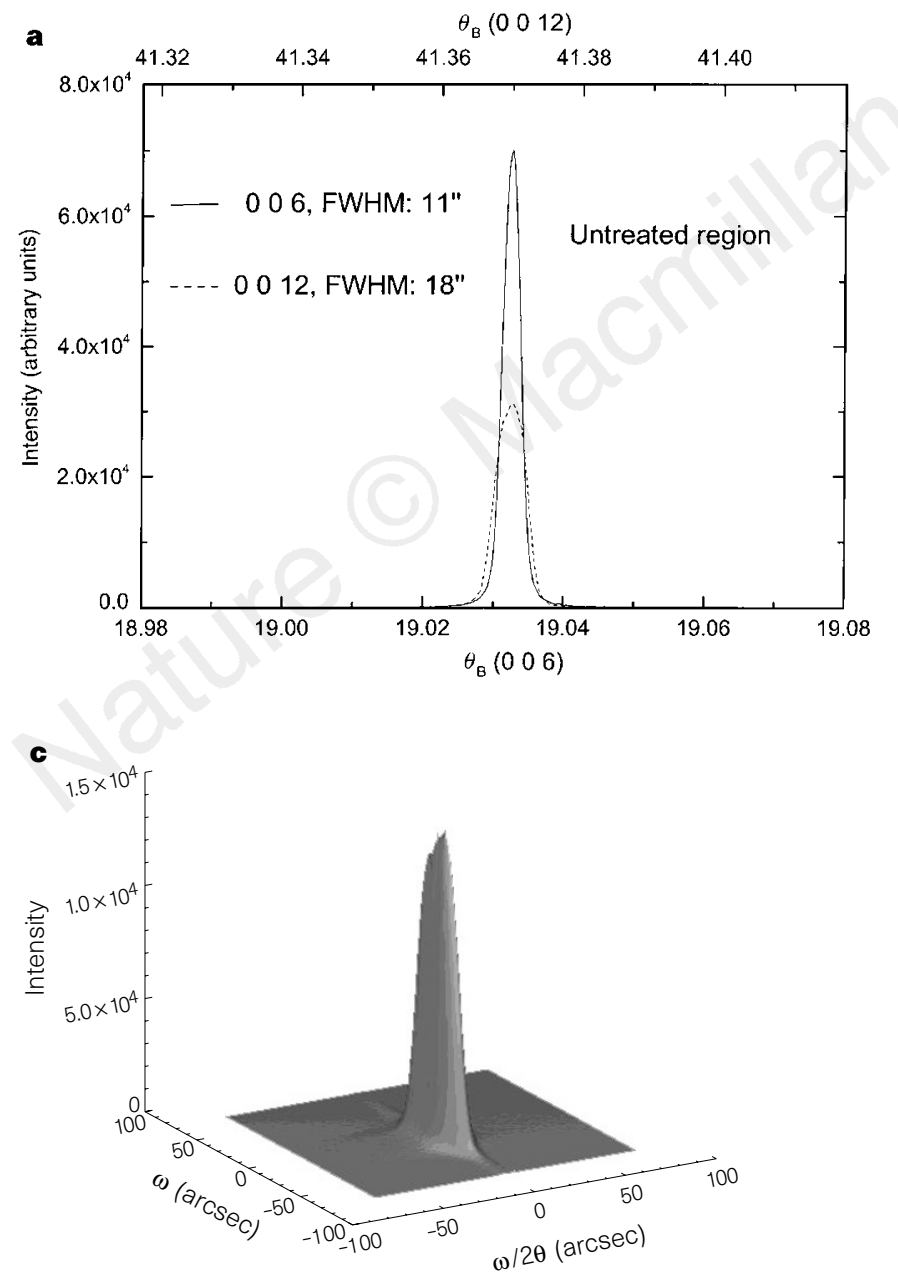

Figure 3 High-resolution diffraction patterns and diffraction-space maps. $\mathbf{a}$ and $\mathbf{b}$ show a comparison between the 006 and 0012 rocking curves from the untreated region and those from the domain-inverted region. The FWHM of the 006 reflection is larger than that of the 0012 reflection measured from the domain-inverted region, which is contrary to the measurements obtained from the untreated region. $\mathbf{c}$ and $\mathbf{d}$ are the 006 and 0012 diffraction-space maps measured from the same domain-inverted region as that for the above rocking represent the tie points $\mathrm{T}_{2}$ and $\mathrm{T}_{2^{\prime}}$. The outside diffracted waves from equation (2) can be written

$$
\mathbf{D}_{\mathrm{g}}^{\mathrm{e}}=D_{\mathrm{g}_{2}} \exp \left[2 \pi i\left(v t-\mathbf{K}_{\mathrm{g}_{2}} \cdot \mathbf{r}\right)\right]+D_{\mathrm{g}_{2}} \exp \left[2 \pi i\left(v t-\mathbf{K}_{\mathrm{g}_{2}} \cdot \mathbf{r}\right)\right]
$$

where $\mathbf{K}_{\mathrm{g}_{2}}$ and $\mathbf{K}_{\mathrm{g}_{2}}$ are the outside wavevectors of the diffracted waves excited for the tie points $\mathrm{T}_{2}$ and $\mathrm{T}_{2^{\prime}}$. These two wavevectors make a small angle of $\Delta \phi(\Delta \phi=\Delta \omega)$, and are different in magnitude by $\left|\mathbf{K}_{\mathrm{g}_{2^{\prime}}}-\mathbf{K}_{\mathrm{g}_{2}}\right|$ which determines the periodicity of interference fringes. The total diffracted intensity is

$$
I=D_{\mathrm{g}_{2}}^{2}\left\lceil 1+R^{2}+2 R \cos 2 \pi\left(\mathbf{K}_{\mathrm{g}_{2^{\prime}}}-\mathbf{K}_{\mathrm{g}_{2}}\right) \cdot \mathbf{r}\right\rceil
$$

where $R=D_{\mathrm{g}_{2}} / D_{\mathrm{g}_{2}}$, the ratio of the amplitudes of the diffracted waves of tie points $T_{2}$ to $T_{2}$.

The intensity given by equation (4) contains the phase factor, $\left(K_{\mathrm{g}_{2}},-K_{\mathrm{g}_{2}}\right) \cdot \mathbf{r}$, and is modulated with a spatial periodicity $\left|\mathbf{K}_{\mathrm{g}_{2^{\prime}}}-\mathbf{K}_{\mathrm{g}_{2}}\right|^{-1}$. The phase factor is independent of the choice of origin; the resultant pattern of interference actually represents a phase map of the periodically domain-inverted structure. The quantity $\left|\mathbf{K}_{g_{2}}-\mathbf{K}_{\mathrm{g}_{2}}\right|^{-1}$ is equal to $\lambda / \Delta \phi$, where $\lambda$ is the wavelength in vacuum (we note that the interference effect takes place outside
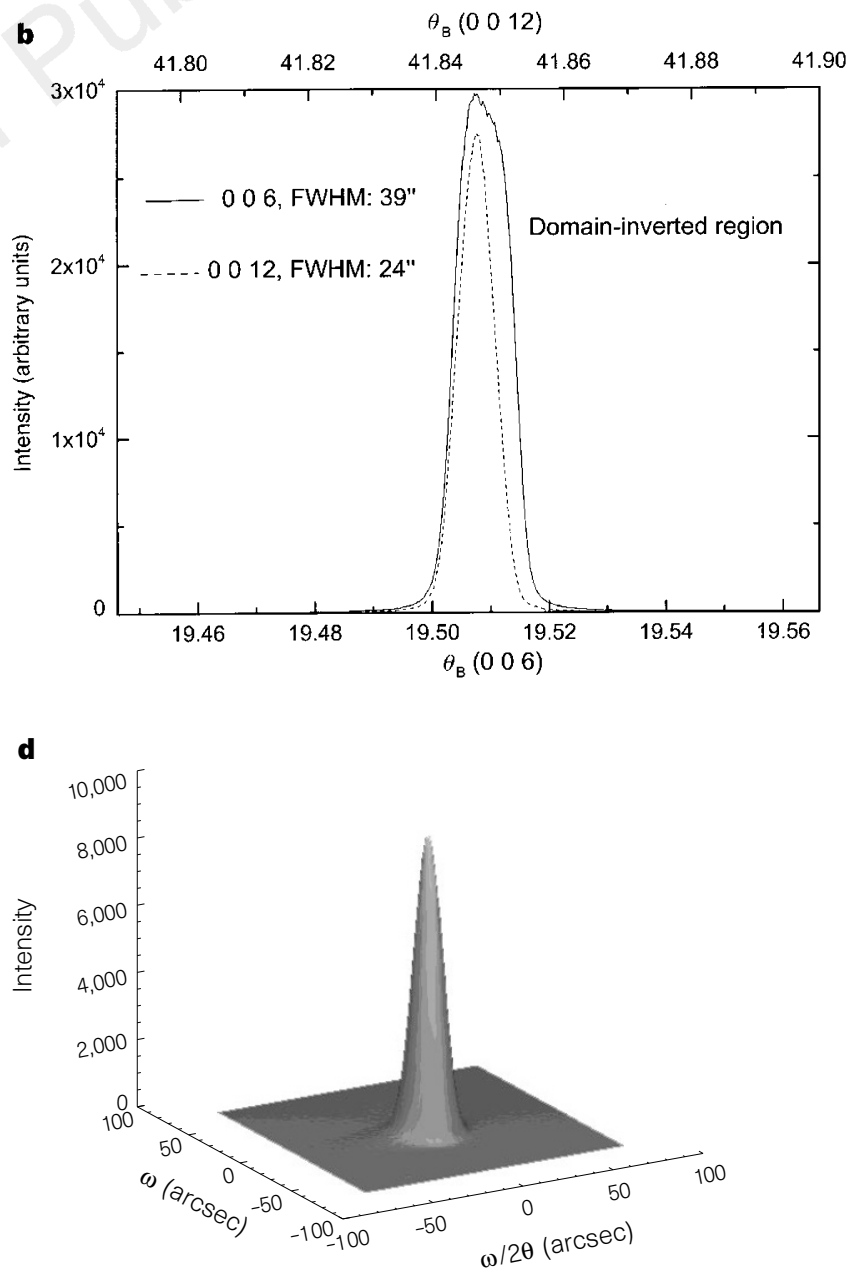

curves, which shows that lattice tilting near the surface is responsible for the broadening of the 006 rocking curve. We note that the intensity distribution is much wider along the $\omega$ than $\omega / 2 \theta$ scan directions in the 006 diffraction-space map because of the overlapping of the two peaks. The sample is orientated so that the domain walls are perpendicular to the plane of incidence of the X-ray beam. 
the crystal). Therefore, the periodicity of interference fringes is inversely proportional to the degree of lattice tilting, which is similar to the formation of Moire fringes ${ }^{5,16-18}$. The tilts of the lattice planes vary with depth, from a few to 10 arcsec. The fringe patterns obtained at different sample-to-film distances arise from interference of different parts of the divergent cones defining the coherently-related beams. These different parts of the beams make different angles with each other, for example, $\sim 5 \times 10^{-5}, 3 \times 10^{-5}$ and $2 \times 10^{-5}$ rad in Fig. 2b, c, d, respectively. Clearly, it is impossible for the $\mathbf{K}_{\mathrm{g}_{2}}$ and $\mathbf{K}_{\mathrm{g}^{\prime}}$, wavefronts with an angle of the order of $10^{-5} \mathrm{rad}$ to overlap inside the crystal or at the sample surface. These two diffracted wavefronts with a lateral displacement within the transverse coherence length of, say, 5-10 $\mu \mathrm{m}$, overlap at a distance of $10-100 \mathrm{~mm}$ from the sample, which yields interference. The phase-contrast nature of X-ray images would disappear if the detector-to-sample distance were not sufficiently large to ensure the overlap of the two coherently-related beams. The visibility of interference fringes, defined by $V=\left(I_{\max }-I_{\min }\right) /\left(I_{\max }+I_{\min }\right)$, is equal to $2 R /\left(1+R^{2}\right)$, where $I_{\max }=D_{\mathrm{g}_{2}}\left(1+R^{2}+2 R\right)$ and $I_{\min }=$ $D_{\mathrm{g}_{2}}\left(1+R^{2}-2 R\right)$. The closer to the value of unity the ratio of the

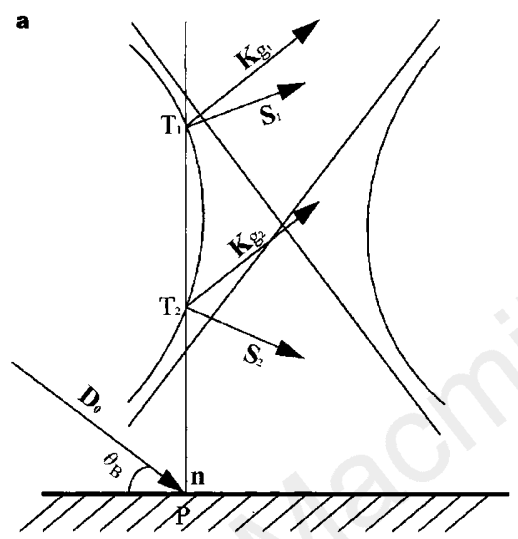

b

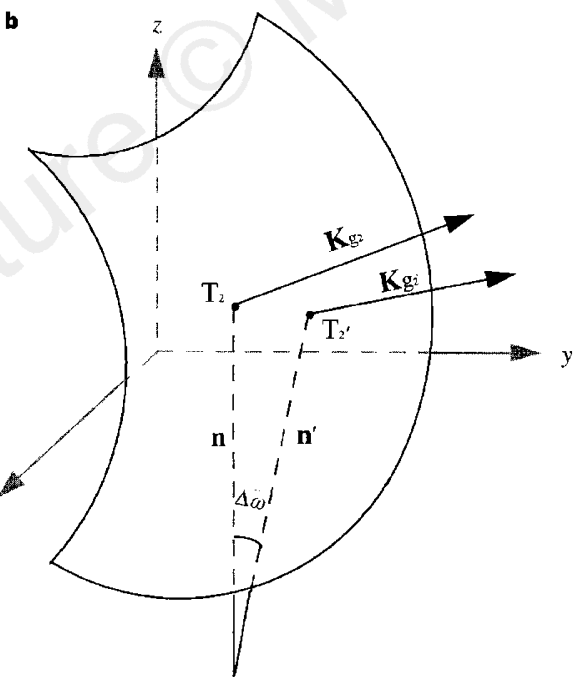

Figure 4 Dispersion surface showing the tie points of wavefields in the symmetric Bragg case. a, Two-dimensional drawing of the dispersion surface in the normal case. The tie points, $T_{1}$ and $T_{2}$ on dispersion surface (hyperbola) are determined by the entrance point $P$ and the crystal surface normal $\mathbf{n}$. Only the tie point $T_{2}$, which has its Poynting vector pointing into the crystal, is excited for a semiinfinitely thick crystal. b. 'Three-dimensional' drawing of a segment of the dispersion surface to show the division of the wavefields by the lattice tilting between two parts of a crystal. Because of lattice tilting, the crystal surface normal is split into $\mathbf{n}$ and $\mathbf{n}^{\prime}$, which leads to the excitation of two wave points, $T_{2}$ and $T_{2}$. Interference would take place between the wavefield of wavevector $\mathbf{K}_{\mathrm{g}_{2}}$ and that of wavevector $\mathbf{K}_{\mathrm{g}_{2}}$. Note that the wave points, $\mathrm{T}_{2}$ and $\mathrm{T}_{2^{\prime}}$, have their Poynting vectors pointing into the crystal. amplitudes $D_{\mathrm{g}_{2}} / D_{\mathrm{g}_{2}}$, the larger $V$ is and the clearer the fringes are. As $D_{\mathrm{g}_{2}} / D_{\mathrm{g}_{2^{\prime}}}=1, I_{\max }=4 D_{\mathrm{g}_{2}}^{2}, I_{\min }=0$, the visibility of the fringes reaches $100 \%$. Because of constructive and destructive interference the black and white contrast in Fig. $2 b-d$ is very striking compared with the diffraction-dominant contrast in Fig. 2a. As expected from equation (4), the fringes run parallel to the horizontal direction. The fringe patterns revealed represent the lattice deformations in the domain-inverted regions. It appears that the strongest contrast occurs at the domain walls where the lattice deformation, and therefore the phase gradient, is different from the other regions. The interference fringes bend wherever both a tilt and a strain are present. The vertical white and black contrasts in Fig. 2a, b, c, e are the images of dislocations in which the horizontal fringes have been modified or even disrupted because of the presence of strong strain fields.

The exploitation of phase-contrast imaging using highly coherent $\mathrm{X}$-ray beams provided by advanced synchrotron radiation sources opens up many possibilities for future research in materials science, condensed-matter physics and biological science. The present method uses the beams diffracted from the sample in either Bragg or Laue geometry for phase-contrast imaging, which differs from the Bonse-Hart interferometer-based technique ${ }^{5,19,20}$ and the transmission-beam-based methods ${ }^{3,4}$ and, therefore, allows non-destructive phase mapping of both highly and weakly absorbing single crystals. Because of the high sensitivity to deformation intrinsic to this method, it can be effectively used for the investigation of defects and microstructure in extensive bulk and thin-film materials such as used in optoelectronics and/or photonics. Use of the phase information obtained from imaging is expected to advance our understanding of the various post-growth modifications which have been extensively used in the fabrication of novel devices.

Note added in proof: It has recently come to our attention that there is another physical interpretation of the phase-contrast images shown here by P. Cloetens, P. Rejmankova and J. Baruchel (personal communication) which supposes a different physical origin for the phase jumps occurring at the domain walls and does not invoke lattice distortions.

Received 1 May; accepted 4 November 1997.

1. Born, M. \& Wolf, E. Principles of Optics 6th edn (Pergamon, Oxford, 1980).

2. Cowley, J. M. Diffraction Physics 3rd edn (North-Holland, Amsterdam, 1995).

3. Davis, T. J., Gao, D., Gureyev, T. E., Stevenson, A. W. \& Wilkins, S. W. Phase-contrast imaging of weakly absorbing materials using hard x-rays. Nature 373, 595-598 (1995).

4. Snigirev, A., Snigireva, I., Kohn, V., Kuznetsov, S. \& Schelokov, I. On the possibilities of x-ray phase contrast microimaging by coherent high-energy synchrotron radiation. Rev. Sci. Instrum. 66, 54865492 (1995).

5. Bonse, U. \& Hart, M. An x-ray interferometer. Appl. Phys. Lett. 6, 155-156 (1965).

6. Cloetens, P., Barret, R., Baruchel, J., Guigay, J.-P. \& Schlenker, M. Phase objects in synchrotron radiation hard x-ray imaging. J. Phys. D 29, 133-146 (1996).

7. Baruchel, J. in X-ray and Neutron Dynamical Diffraction: Theory and Applications (eds Authier, A., Lagomarsino, S. \& Tanner, B. K.) 199-210 (Plenum, New York, 1996).

8. Armstrong, J. A., Bloembergen, N., Ducuing, J. \& Pershan, P. S. Interactions between light waves in a nonlinear dielectric. Phys. Rev. 127, 1918-1939 (1962).

9. Hu, Z. W. Thomas, P. A. \& Webjörn, J. High-resolution x-ray characterization of periodically domain-inverted nonlinear optical crystals. J. Phys. D 28, A189-A194 (1995).

10. Hu, Z. W., Thomas, P. A. \& Webjörn, J. Observation of periodic domain inversion in periodically poled $\mathrm{LiNbO}_{3}$ by high-resolution topography. J. Appl. Crystallogr. 29, 279-284 (1996).

11. Hu, Z. W., Thomas, P. A. \& Risk, W. P. Periodic domain inversion in poled $\mathrm{KTiOPO}_{4}$ via highresolution x-ray topography and diffraction-space mapping. J. Phys. D 29, 2696-2704 (1996).

12. Fewster, P. F. A high-resolution multiple-crystal multiple-reflection diffractometer. J. Appl. Crystallogr. 22, 64-69 (1989).

13. Authier, A. Trajet des rayons $\mathrm{X}$ dans un cristal parfait au voisinage de la réflexion totale. J. Phys. Radium. 23, 961-969 (1962).

14. Batterman, B. W. \& Cole, H. Dynamical diffraction of x-rays by perfect crystals. Rev. Mod. Phys. 36, 681-716 (1964).

15. Tanner, B. K. X-ray Diffraction Topography (Pergamon, Oxford, 1976).

16. Lang, A. R. \& Miuscov, V. F. ̊̊-scale displacements revealed by x-ray Moiré topographs. Appl. Phys. Lett. 7, 214-216 (1965)

17. Bonse, U. \& Hart, M. Moiré patterns of atomic planes obtained by x-ray interferometry. Z. Phys. 190, 455-467 (1966).

18. Lang, A. R. X-ray Moiré topography of lattice defects in quartz. Nature 220, 652-657 (1968).

19. Hart, M. Bragg reflection x-ray optics. Rep. Prog. Phys. 34, 435-490 (1971).

20. Ando, M. \& Hosoya, S. in Proc. 6th Int. Conf. on X-ray Optics and Microanalysis (eds Shinoda, G. et al.) 63-68 (Univ. Tokyo Press, 1972).

Acknowledgements. Z.W.H. was on leave from the National Laboratory of Solid State Microsctructures, Nanjing University, China. Z.W.H. thanks A. R. Lang for discussions, and was supported by the UK EPSRC.

Correspondence and requests for materials should be addressed to P.A.T. (e-mail: phrve@csv.warwick.ac.uk). 